\title{
DEL SUJETO EPISTEMOLÓGICO AL HORIZONTE TRANSLÓGICO DE LA VIDA HUMANA. UN ESTUDIO CRÍTICO DEL PROBLEMA DE LA FUNDAMENTACIÓN DE LA LÓGICA EN LOS PRIMEROS ESCRITOS DE HEIDEGGER (1912-1916)*
}

JESÚS ADRIÁN ESCUDERO

DEPARTAMENTO de FILOSOFIA FACULTAD DE LETRAS

UNIVERSIDAD AUTÓNOMA DE BARCELONA

Desde el inicio de su carrera, Heidegger se dedicó con afán al estudio de la lógica y de la matemática. Entre los años 1912 y 1916, publica una serie de artículos y trabajos en los que se ocupa de diversa manera de las principales teorías lógicas de su época, tanto de la neoescolástica y el neokantismo como del realismo crítico de Külpe y la fenomenología de Husserl. Este interés precoz por temas relacionados con la lógica se inicia con sus primeros artículos sobre "El problema de la realidad en la filosofía moderna" (1912) y "Nuevas investigaciones sobre lógica" (1912), toma cuerpo en la tesis doctoral, La doctrina del juicio en el psicologismo (1913), se desarrolla en el escrito de habilitación, La doctrina de las categorías y del significado en Duns Escoto $(1915)^{1}$ y culmina finalmente en el grueso de las lecciones de Marburgo $(1925-1928)^{2}$ No obstante, desde de su conferencia

* El presente trabajo se inscribe en el Proyecto de Investigación PB 96-1144 del Ministerio de Educación y Cultura, y también es un proyecto financiado por la Direccio General de Recerca de la Generalitat de Catalunya (1999BEAI00229).

1 Todos estos trabajos están recopilados en el volumen primero de la edición de las Obras Completas de Heidegger, Primeros escritos (cfr. GA 1: 1-16, 17-44, 55-187 y 189-412, respectivamente).

2 Véanse las lecciones del semestre de invierno de 1925-1926, Lógica. La pregunta por la verdad (GA 21), y las lecciones del semestre de verano de 1928, Los primeros fundamentos metafísicos de la lógica (GA 26). En este sentido, la publicación de la primera edición de Frühe Schriften en 1972 y la aparición gradual desde 1976 de las lecciones anteriores a Ser y tiempo en el marco de la Gesamtausgabe volvieron a reactivar el interés de los especialistas por este periodo de la vida intelectual de Heidegger. A los ya clásicos trabajos en torno a las vinculaciones heideggerianas con el neokantismo y el campo de la lógica de los años setenta de 
inaugural en Friburgo, en 1929, su pensamiento a menudo ha sido tachado de antilogicista e irracionalista.

Frente a esta imagen algo reduccionista y proclive a soslayar la obra del joven Heidegger, el presente artículo pretende determinar la temprana posición de Heidegger respecto a la lógica y ver cómo los resultados de su investigación se van integrando en la búsqueda de un fundamento sólido del conocimiento humano, que paulatinamente se irá desplazando hacia la cuestión ontológica de la pregunta por el sentido del ser. Su búsqueda se orienta en estos primeros escritos hacia una manera de ser concreta, el ser como algo verdadero. Esta determinación se lleva a cabo en el juicio, es decir, se deja transportar al universo de lo puramente lógico. Se emprende así una revisión preliminar y necesaria de la naturaleza de la lógica en el contexto de la disputa con el psicologismo (1). Una vez demostrada la irreductibilidad de la realidad lógica y la psicológica, se plantea el interrogante por la relación existente entre la dimensión lógica del sentido y el ser de los entes (2). Responder a esta pregunta supone enfrentarse con la postrera y más alta tarea de la filosofía: una doctrina de las categorías capaz de estructurar el ámbito global del ser en sus diferentes formas de realidad. En su trabajo de habilitación, Heidegger se preguntará por el lugar que corresponde a la forma de ser del sentido en el reino del ente. Eso lo colocará por primera vez, tal como lo reconoce en el prólogo a la primera edición de Frühe Schriften, ante dos cuestiones que ya no lo abandonarán jamás: "En la forma del problema de las categorías con la pregunta por el ser, en la forma de la doctrina de los significados con la pregunta por el lenguaje." ${ }^{3} \mathrm{Al}$ final de su trabajo, el dilema ¿cómo es en general posible que el sentido valga respecto de los objetos? recibe una respuesta metafísica. No es posible ver la lógica en su verdadera dimensión sin el horizonte translógico en el que se fundamenta. Con esta solución ontológica, el joven Heidegger podrá despojarse de los eslabones de la concepción epistemológica del sujeto y abrirse paso hacia una comprensión temporal y dinámica de la vida humana (3).

Borgmann (1978), Caputo (1973) y (1974), Fay (1974), Gumppenberg (1974), Hobe (1971) o Stewart (1979), se sumaron en los ochenta los de Kisiel (1983), Mohanty (1988) o Wolzogen (1989), hasta la explosión de estudios aparecidos en los noventa, merced a la publicación casi integra de la obra temprana de Heidegger, como los de Borges (1995), Buren (1994), Crowell (1992) y (1994), Courtine (1996), Fehér (1992), García Gainza (1997), Kisiel (1996), Orth (1992) o Rampley (1994). Consúltense las referencias bibliográficas completas al final del trabajo.

3 GA 1: 55 . Aquí ya empieza a hacerse consciente la relación entre la pregunta por el ser y la pregunta por el lenguaje; una relación llamada a determinar su futuro camino filosófico. 


\section{La naturaleza de la lógica}

\subsection{Definición y ámbito de la lógica}

La pregunta ¿qué es la lógica? aparece como una cuestión inextricablemente entrelazada con la cuestión del ser, hasta el punto que ésta permanece opaca, incluso deviene ininteligible, si no la reconducimos al terreno de una interrogación primaria acerca del significado. No olvidemos que la pregunta por el ser se dirige fundamentalmente a esclarecer el sentido del ser, de modo que al devolverla a su contexto de origen nos sitúa de nuevo ante la problemática del juicio, de la verdad y de la constitución categorial del ser. El asunto es puesto en escena desde 1912 en las Nuevas investigaciones sobre lógica. En efecto, el objetivo de este artículo queda fijado desde la primera línea: ofrecer una reflexión crítica de los principios mismos de la lógica. ${ }^{4}$ Después de repasar las últimas investigaciones en el campo de la lógica, que junto a Husserl incluye una notable mención a Frege y a Russell, sigue en pie la cuestión del princpio: “¿Qué es la lógica? Esta cuestión ya nos coloca ante un problema cuya solución está reservada al futuro." ${ }^{5}$ Ciertamente los escritos de esta primera etapa, entre 1912 y 1916, se adscriben a temas del ámbito de la lógica, particularmente a la problemática de la validez como primer nivel de manifestación del ser en los juicios. ${ }^{6}$

La definición tradicional y trivial de la lógica en términos de una ciencia normativa del pensamiento, una disciplina que establece las reglas que uno debe seguir para la formulación de proposiciones verdaderas, peca para el joven Heidegger al menos de una doble ambigüedad: por un lado, no queda claro si el término "pensamiento" está referido al proceso de pensar o al contenido del pensamiento; por otro lado, tampoco resulta evidente cuándo el concepto de "verdad" remite a la verdad formal o a la verdad material. Teniendo en cuenta estas acotaciones, se puede redefinir el objetivo de la lógica del modo siguiente: la lógica es una ciencia que da validez a las estructuras de sentido o formas de significación. Precisamente su disertación de 1913, presentada como una contribución crítico-positiva de la lógica, llega a una conclusión singularmente husserliana de una lógica pura del significado: los lógicos deben tratar de descubrir el significado preciso de

4 Cfr. GA 1: 17.

5 Cfr. GA 1: 12

6 Cfr. Courtine (1996), pp. 13-18. El mismo autor ofrece después una interesante exposición de la destrucción crítica de la lógica a partir de las lecciones de 1925-1926 y de la conferencia de 1929 ¿Qué es metafísica? El núcleo de la argumentación heideggeriana pasa por denunciar la escolarización de la lógica, que trae como consecuencia una determinación del juicio como el lugar de la verdad, desestimando la originaria capacidad de desvelamiento inherente al lógos. 
los enunciados, luego han de proceder a determinar las formas del juicio en relación con los diferentes ámbitos de realidad para, finalmente, encuadrar estas formas en un sistema. ${ }^{7}$ Una toma de posición que, en estos primeros trabajos, ya muestra su temprana inclinación a afrontar la lógica desde la óptica de la validez del sentido en detrimento del proceso mental de pensar. "La existencia psíquica de un concepto y el contenido ideal del concepto son dos cosas completamente distintas." 8

Heidegger retoma aquí, en referencia a Frege y a Husserl, la crítica del psicologismo. En este contexto se enmarca el mencionado artículo, Nuevas investigaciones sobre lógica, en el que se adentra críticamente en el territorio de la lógica matemática. Heidegger adopta una postura muy próxima a Heinrich Rickert. Su distinción entre el carácter nomotético y generalizante de las ciencias naturales y el carácter ideográfico e individualizante de las ciencias históricas, lo empuja a explorar la realidad de la lógica en la esfera de la autonomía del sentido. El objeto de estudio de la lógica pura es la validez del sentido del juicio. Pero Heidegger, fiel al espíritu husserliano, no puede evitar preguntarse: "¿qué es esto, el sentido?"9 La respuesta aparece en el capítulo final de la disertación:

El sentido se halla en la más estrecha conexión con aquello que designamos de manera general con pensar; pero por pensar no comprendemos el concepto amplio de representación, sino el pensar que puede ser correcto o incorrecto, verdadero o falso. A cada juicio le acompaña, pues, un sentido inmanente. La forma real y efectiva del sentido es la validez [...] Reconocimos la validez como la forma real y efectiva de la lógica; es el sentido el que vale y el que, por tanto, "encarna" la lógica. (GA 1: 172)

Las investigaciones de Heidegger asignan claramente a la lógica el dominio de la validez.

Sin embargo, la cuestión del sentido no es ajena al problema de la valoración que acompaña a toda captación del ser. ¿Acaso, se pregunta el joven doctorando, no interviene en el represantar mismo un momento axiológico? ¿Es que puede darse una captación del ser que no sea ya valorativa? La convicción profunda de que en toda aprehensión del ser concurre un acto de valoración sirve de hilo conductor para adentrarse en los trabajos de la primera época heideggeriana.

En 1912, Heidegger argumenta que la lógica no consigue desvincularse de los conceptos y símbolos matemáticos y que, por consiguiente, no logra penetrar en los principios lógicos mismos. El formalismo de la lógica

7 Cfr. GA 1: 185-186.

8 GA 1: 7.

9 GA 1: 170. 
matemática, en cuanto cálculo de proposiciones, no es consciente de los problemas de una teoría del juicio. ${ }^{10} \mathrm{Y}$ ¿cuáles son esos problemas? Al menos tres: la naturaleza de los juicios negativos, la naturaleza de la cópula y la predicación, y, por último, el problema de la verdad. Además, una.lógica de este tipo tampoco tiene en consideración la cuestión de su fundamentación. El estudio de las condiciones de posibilidad de la matemática y de la lógica, afirma Heidegger, no tiene cabida en ninguna de estas dos disciplinas. ${ }^{11}$ Este enfrentamiento con la lógica matemática conduce a Heidegger al desarrollo gradual de una lógica filosófica. En opinión de Heidegger, esta lógica filosófica ha alcanzado su máximo apogeo en autores como Aristóteles, Leibniz, Kant y Hegel. Considera que entre sus contemporáneos destaca Lask, de quien afirma que ha sido el pensador que de forma más consciente ha perseguido una comprensión filosófica de la lógica, mientras que reprocha a Husserl no haber aprovechado las posibilidades contenidas en la fenomenología para un tratamiento filosófico de la lógica, pues considera a ésta una ciencia separada, una disciplina formal independiente de la filosofía.

Entonces, ¿cuáles son las tareas y los problemas que Heidgger cree que son propios de la lógica filosófica? Ante todo, no es una disciplina nueva; más bien actualiza un telos que ha caracterizado a la historia de la lógica. ${ }^{12}$ Ahora bien, ¿cómo acometemos el estudio de una lógica filosófica? ¿Acaso determinamos primero qué es filosofía y luego aplicamos este concepto a la lógica? O, por el contrario, ¿empezamos por la lógica tradicional y abordamos los principales problemas contenidos en ella de tal manera que nos guíen a la filosofía? Heidegger apuesta por la segunda opción, porque sin duda poseemos ya cierta comprensión histórica de la lógica. A partir de esta comprensión previa podemos interrogar a la lógica por sus potencialidades filosóficas.

Además, ¿qué elementos nos trasladan de la lógica tradicional a la lógica filosófica? El juicio. En concreto, su estructura intencional y predicativa, así como su valor de verdad y su ámbito de validez. Sin embargo, ¿cómo se entieñde esta estructura intencional? ¿Qué es la predicación y qué papel desempeña en una teoría del juicio? ¿Cuál es la estructura del juicio que le permite la doble posibilidad de ser o bien verdadero o bien falso? ¿Qué tipo de relación guarda la verdad con el juicio? ¿Es una propiedad el juicio? Además, ¿existe una verdad teorética y otra práctica? ¿Cuál de las dos encierra el sentido primario de la verdad? Y ¿cuál es el fundamento metafísico de la

10 Una objeción similar reaparece en Ser y tiempo, obra en la que Heidegger tilda a la lógica de disolver el juicio en un sistema de asignaciones, conviertiéndolo en "un objeto de cálculo, pero no en tema de una interpretación ontológica” (SuZ: $\S \S 33,159$ / SyT: 178).

11 Cfr. GA 1: 42-43. Véase también Fay (1974), pp. 77-79.

12 Cfr. Mohanty (1988), pp. 113-115. 
lógica? Toda un cúmulo de interrogantes que habrán de ir encontrando una solución en el transcurso de la evolución del pensamiento de Heidegger.

\subsection{La refutación del psicologismo}

Hacia 1900, las ciencias naturales, en colaboración con el positivismo, el materialismo y el pragmatismo, parecen haber arrinconado a la filosofía. ${ }^{13}$ El sentimiento de triunfo de las ciencias se funda en el conocimiento cada vez más exacto de la naturaleza y en el creciente dominio técnico de la misma. Se implanta una lógica de la investigación científica basada en la observación, la formulación de hipótesis y la verificación. La pregunta filosófica por antonomasia acerca de "qué es algo" va perdiendo terreno ante la cuestión eminentemente utilitarista de "cómo funciona algo". La fe en el progreso reduce toda actividad espiritual del ser humano a mera función cerebral. En este sentido, diversos representantes del materialismo irrumpen en el mercado editorial a mediados del siglo pasado: Karl Vogt con sus Cartas fisiológicas (1845), o Jakob Moleschott con Fuerza y materia (1855). Elementos de este gradual auge de la ciencia quedan reflejados en el realismo y en el naturalismo de la literatura, en consonancia con las ideas biológicas sobre el hombre. La razón humana no es sino un instrumento más de selección natural, la razón no es sino un mecanismo más de adaptación a la naturaleza.

Paralelamente, asistimos al nacimiento y a la difusión del pragmatismo anglosajón de William James y Charles Peirce, que arranca a la verdad de su anclaje en el reino de las ideas y la rebaja a la condición de un principio social de autorregulación de la acción humana. El criterio de la verdad descansa en el éxito práctico y se acredita en la eficiencia lograda por el método del intento y del error. Desde esta óptica adaptativa, la biología de la evolución de Darwin viene a confirmar que no sólo nosotros, sino también la naturaleza entera llega por el error al éxito. Y confiere con ello una evidencia casi insuperable al principio de que la verdad no es más que éxito práctico.

El principio de este enfoque de las ciencias naturales se extrapola rápidamente al estudio de las ciencias humanas, de entre las cuales se destaca la psicología. El estudio de los mecanismos de lo psíquico lleva a buscar las leyes explicativas de la transformación de los estímulos fisiológicos, de las estructuras regulares de la asociación de las representaciones mentales y, finalmente, conduce a averiguar cuáles son los principios lógicos del

13 Rüdiger Safranski y Ernst Nolte ofrecen una interesante exposición del clima intelectual y filosófico de este periodo y de su influencia en esta primera etapa de la vida de Heidegger (cfr. Safranski (1994), pp. 42-57 y Nolte (1998), pp. 36-53). 
pensamiento mismo. Sin embargo, desde esta perspectiva psicologista las reglas del pensamiento se convierten en leyes naturales, pasando desapercibido que la lógica no describe empíricamente cómo pensamos, sino que dice cómo hemos de pensar. Las investigaciones de Husserl, como veremos posteriormente, se proponen liberar la lógica de las redes del naturalismo y poner nuevamente de manifiesto su carácter normativo.

En este contexto, el idealismo ha dejado de ser la corriente filosófica dominante en Alemania a partir de 1830, debido a diversas causas que abarcan desde lo político, una excesiva identificación del idealismo hegeliano con el autoritarismo prusiano, hasta lo científico y filosófico, una filosofía de la naturaleza que choca contra las evidencias experimentales. El resultado de todas estas circunstancias es la puesta en cuestión de la filosofía misma y el comienzo de una nueva tradición que pretende enfocar los problemas desde una perspectiva más científica. De este modo, entra en escena durante la primera mitad del siglo xIx el término "psicologismo". Así pues, en un principio la psicología se muestra en diferente medida como el suelo firme en que apoyar la filosofía frente al puro idealismo especulativo. A partir de este punto de vista, y en medio de las condiciones citadas, se desarrolla en Alemania a lo largo del siglo xIx un naturalismo filosófico que incluye, en la mayor parte de los casos, el psicologismo en lógica, es decir: tratar a la lógica como ciencia descriptiva de determinados procesos mentales, más que como ciencia normativa de los mismos.

Pero a pesar de la pujanza del naturalismo filosófico entre 1830 y 1870 , éste no deja de tener sus detractores: esencialmente entre aquellos filósofos que se resisten a que la tradición filosófica sea engullida sin más por las ciencias naturales. El caso de Rudolf Hermann Lotze encarna quizá un ejemplo emblemático de resistencia a esa creciente hegemonía positivista. ${ }^{14}$ Lotze, aun reconociendo el valor y la significación de las ciencias naturales, insiste, sin embargo, en la distinción de los actos psicológicos de pensar, que existen como algo temporalmente localizable, y los contenidos de esos actos, cuyo modo de existencia es su validez intemporal. ${ }^{15}$ Este rechazo del naturalismo filosófico y, en particular, de la presentación psicologista de la filosofía pasará a ser moneda corriente, a finales del siglo xIx y principios del xx, entre los neokantianos de las escuelas de Marburgo y Baden con su proclama de la independencia de los valores de los hechos de la experiencia psicológica. Brentano y Husserl, que comenzaron su carrera filosófica abra-

14 Una actitud en sintonía con la crítica de Lange a esas actitudes intelectuales se encuentra en su obra, Historia del materialismo (1866), en la que propone restablecer la distinción kantiana entre naturaleza y espíritu, entre determinismo y libertad, entre leyes y valores.

15 Una distinción que luego Heidegger retoma sin apenas modificarla. Cfr., por ejemplo, GA 1: 22 y 323 ss. 
zando el naturalismo, rectifican más adelante sus posiciones respecto de la lógica. En este escenario también cabría tener presente la crítica de Frege al psicologismo. Veamos un poco más en detalle las refutaciones del psicologismo de estos dos últimos pensadores, ya que en buena parte inspiran las reflexiones del propio Heidegger. ${ }^{16}$

La refutación del psicologismo de Frege se enmarca en la búsqueda de un fundamento sólido para la aritmética. Su propósito original es introducir rigor absoluto en los métodos de prueba de la matemática. Para ello, considera necesario construir un lenguaje simbólico en el que pueda llevar a cabo las demostraciones con la garantía de que no se deslicen errores debido al uso incontrolado de la intuición. Precisamente uno de los objetivos de su artículo Sobre sentido y referencia (1892) va dirigido a la construcción de un lenguaje lógicamente perfecto y depurado de la influencia del lenguaje natural ordinario, una tarea que el mismo Frege considera de difícil cumplimiento. "Es verdad que en un conjunto perfecto de signos, a cada expresión debería corresponderle un sentido determinado; pero las lenguas naturales a menudo no cumplen este requisito, y hay que darse por satisfecho si, sólo en un mismo contexto, tiene la misma palabra siempre el mismo sentido."17

Ahora bien, la realización de este propósito requiere un examen previo de la estructura formal de los enunciados que componen las demostraciones, lo que supone someter a análisis la función del lenguaje. Con ese cambio de perspectiva, que de alguna manera se inscribe en el giro lingüístico del pensamiento filosófico del siglo xx, Frege se distancia de la tendencia imperante desde Descartes de considerar los problemas de la filosofía desde posicionamientos estrictamente epistemológicos. Frege piensa que las preguntas sobre las capacidades de la mente humana de penetrar y conocer el mundo exterior no deben ser el tema central de la filosofía. Así, estudiar cómo adquirimos nuestras ideas y cuál es su naturaleza resulta irrelevante. La posesión de un concepto es algo que se manifiesta a través del uso del lenguaje, de modo que el análisis de los conceptos no es algo distinto del análisis del funcionamiento del lenguaje. La pregunta acerca de si es posible que nuestra mente conozca una realidad exterior se vuelve superflua dado que ya tenemos ese conocimiento. El problema no es, por consiguiente, determinar si es posible lograr conocimiento, sino mostrar las condiciones

16 En el citado artículo, Nuevas investigaciones sobre lógica (1912), Heidegger destaca el papel relevante que ocupa Frege en la filosofía de la matemática (cfr. GA 1: 20). En cuanto a la función desempeñada por las Investigaciones lógicas de Husserl en la revitalización de la lógica, topamos con múltiples referencias a lo largo de sus diversos cursos de Friburgo y Marburgo. En las lecciones de 1925-1926 reconoce que la obra de Husserl "ha vuelto a animar la lógica contemporánea y a potenciar sus posibilidades productivà" (GA 21, §4, 24).

17 Cfr. Frege (1991), p. 26. 
y los procedimientos para lograrlo. Estas cuestiones dependen, en opinión de Frege, de una correcta teoría del significado. ${ }^{18}$

Se trata, ahora, de establecer cuál es la relación de las palabras con el mundo, planteándose de inmediato el dilema siguiente: ¿esa relación es directa o indirecta? Frege sosticne en el citado artículo, Sobre sentido $y$ referencia, que esa relación, tanto en el caso de los nombres propios (por ejemplo, "Homero") como en el de las descripciones definidas (en la estela del ejemplo anterior, "el autor de la Odisea"), es indirecta, ya que se produce por medio del sentido. ${ }^{19}$ Las palabras remiten a las cosas de una forma indirecta. Dicho de otro modo, no tenemos un acceso directo a las cosas; nuestra aprehensión del mundo objetivo está mediada por los significados. ${ }^{20}$ Nos hallamos, pues, ante una teoría de la referencia indirecta en la que el significado - dicho en términos fenomenológicos, el modo de ser dado lo designado- se convierte en condición de posibilidad del acceso al referente. En la medida en que el lenguaje es el responsable del modo en que nos aparecen los referentes y, por ello, la instancia que prejuzga como qué son considerados en cada caso, encierra en sí el marco categorial de referencias de todo lo que puede aparecer en ese mundo abierto lingüísticamente. El referir, por tanto, se sitúa en el marco de una previa constitución de sentido inherente a un determinado lenguaje. Por ello, el modo de referirnos a las cosas ya siempre está mediado por el nivel de precomprensión que tenemos en cada caso de las cosas y que nos permite, a su vez, identificar los mismos referentes en tanto compartimos el significado de la expresión referencial. ${ }^{21}$ Así, por ejemplo, para que la oración "La mesa del despacho es de roble" resulte comprensible a alguien, éste tiene que comprender previamente el

18 La misma idea presente en Husserl y en la tesis de habilitación de Heidegger, que da debida cuenta de una gramática pura. Volveremos sobre esta cuestión en el apartado 3.1 .

19 Cfr. Frege (1991), p. 26.

20 En este punto Frege se separa nítidamente de la concepción mentalista del lenguaje, que encuentra en Locke a uno de sus principales defensores al sostener la prioridad ontológica del pensamiento sobre el lenguaje. Según esta tesis, sólo la capacidad de representación mental de los usuarios de un lenguaje confiere significado a las expresiones lingüísticas que la forman. Las palabras deben su significado a los pensamientos de quienes las usan; éstos lo tienen independientemente. La noción de un mundo objetivo, pues, la obtenemos por inferencia a partir de nuestro conocimiento de un mundo mental. Sin embargo, por el camino emprendido por Locke resulta difícil dar cuenta de otros componentes lingüísticos, quizá menos relevantes a primera vista pero igualmente fundamentales para entender el funcionamiento del lenguaje: términos como "y", "con", "todo", "es posible que", que desde la época medieval se vienen denominando sincategoremáticos. Para más información sobre la postura de Frege frente al planteamiento mentalista de Locke, véase García-Carpintero (1996), pp. 98 ss.

21 En el capítulo tercero del presente trabajo veremos hasta qué punto esa comprensión previa que en cada caso ya tenemos de los entes intramundanos se basa en nuestra relación lingüística y simbólicamente mediada con el mundo, que nos posibilita un primer acceso comprensivo a las cosas que inmediatamente nos salen al encuentro. 
significado de las expresiones que aparecen en la oración, "mesa", "despacho", "roble", para poder identificar el referente.

Con todo, ¿qué aporta este enfoque lingüístico de Frege a la crítica del psicologismo? Cualquier lenguaje que pretenda servir de fundamento a la aritmética ha de asentarse en principios puramente lógicos y, por tanto, universalmente válidos. Las cuestiones acerca de la validez no pueden responderse apelando a hechos contingentes de nuestras disposiciones psicológicas. Para Frege, el pensamiento encarna una entidad lógica objetiva y no un simple proceso psicológico subjetivo. De ahí la diferencia que se establece entre sentido y representación. La representación es un acto mental básicamente subjetivo, mientras que el sentido permanece idéntico para los hablantes. ${ }^{22}$

De la referencia y del sentido de un signo hay que diferenciar la representación a él asociada. Si la referencia de un signo es un objeto sensiblemente perceptible, la representación que yo tengo de él es entonces una imagen interna formada a partir de recuerdos de impresiones sensibles que he tenido, y de actividades que he practicado, tanto internas como externas. Esa imagen está frecuentemente impregnada de sentimientos; la claridad de cada una de sus partes es diversa y vacilante. No siempre, ni siquiera en la misma persona, está unida la misma representación al mismo sentido. La representación es subjetiva: la representación de uno no es la del otro. Por ello se dan múltiples diferencias en las representaciones asociadas al mismo sentido. Un pintor, un jinete y un zoólogo asociarán probablemente representaciones muy distintas al nombre "Bucéfalo". Por eso se diferencia la representación esencialmente del sentido de un signo, el cual puede ser propiedad común de muchos y que, por tanto, no es parte o modo de la mente individual. ${ }^{23}$

En el caso de la representación, para ser estrictos, se ha de precisar a quién pertenece y en qué momento se produce. Esto no impide que dos personas conciban el mismo sentido, pero no pueden tener la misma representación. Cuando se representan lo mismo, cada uno tiene su propia representación subjetiva. Pensar como proceso mental es un existir real; el contenido lógico del pensamiento, en cambio, es un existir ideal. El psicologismo se

22 Quizá resulte interesante recordar la analogía que el mismo Frege trae a colación a propósito de la visión de la Luna a través de un telescopio para ilustrar esa diferencia. La Luna es el objeto de observación. Por un lado, tenemos la imagen real que queda dibujada sobre el cristal del objetivo del telescopio; por otro lado, la imagen en la retina del observador. La primera imagen correspondería al sentido, mientras que la segunda a la representación. La imagen formada dentro del telescopio es, en verdad, sólo parcial y depende del lugar de observación, pero con todo es objetiva en la medida en que es la misma para varios observadores. Las imágenes de la retina, sin embargo, pertenecen subjetivamente a cada uno de forma propia (cfr. Frege (1991), p. 28).

23 Frege (1991), p. 27. 
caracteriza concretamente por confundir ambos planos, restringiendo todo pensamiento a la relatividad de los diferentes actos mentales.

Precisamente Husserl denuncia esas mismas consecuencias relativistas del psicologismo en la primera parte de sus Investigaciones lógicas, intituladas "Los prolegómenos a la lógica pura" (1900). Sin embargo, no hay que olvidar que Husserl había comenzado su carrera filosófica bajo el influjo, entonces prevaleciente, del psicologismo. Las leyes lógicas eran a sus ojos meras leyes inductivas, leyes de los hechos de conciencia asentados en la costumbre. En el momento de escribir su Filosofía de la aritmética (1891), el mundo de Husserl estaba construido sobre actos psíquicos. Era un mundo mental, no real. Acerca del mundo real, en el que están las cosas y en el que las unas se relacionan con las otras, sostenía Husserl que no podía afirmarse nada, ya que el conocimiento se limita a los fenómenos psíquicos, es decir, no se refiere a las cosas, sino sólo a su representación. ${ }^{24}$

Sin embargo, el propio Husserl se daría pronto cuenta de que había sido víctima de una extendida enfermedad filosófica, y a partir de 1900 se opondrá con fuerza a toda teoría que sostenga que la razón depende de algo no racional, de algo relativo a la constitución psíquica del hombre o del funcionamiento de sus procesos mentales. Estas cuestiones, que Husserl subsume bajo el nombre de "psicologismo", son objeto de una severa crítica, ${ }^{25}$ en la que se desmantelan los errores psicologistas desde una doble perspectiva: desde sus consecuencias y desde sus prejuicios.

De entrada, Husserl afirma que ninguna teoría puede violar las condiciones que hacen posible toda teoría. Esto es lo que ocurre con la doctrina del juicio en el psicologismo. El juicio lleva consigo una pretensión de validez. Pero si el que juzga no puede en ningún caso justificar esa exigencia, si no existe ningún criterio para distinguir del juicio cierto el prejuicio, entonces no se puede sostener razonablemente ninguna teoría. En consecuencia, al carecer de las leyes que rigen el enlace de las proposiciones de un significado consistente, la noción de verdad se volatiliza, ya que se hace relativa a un modo meramente humano de pensar. No obstante, decir que la verdad es relativa a la constitución psicológica y a las leyes mentales

24 Los equívocos que se desprenden de esa postura psicologista ya los hemos visto anteriormente en Frege. De hecho, el mismo Frege, en una reseña crítica al libro de Husserl, recalca la diferencia existente entre la representación de una cosa y la cosa misma representada. En un comentario no exento de ironía, Frege considera un placer inocente llamar a la Luna una representación, al menos mientras uno no se imagine que puede, por actos psíquicos, moverla de su lugar en el sistema solar (cfr. G. Frege (1894): "Rezension: Husserl, Philosophie der Arithmetik", Zeitschrift für Philosophie und philosophische Kritik 103: 313-332).

25 El mismo Husserl confiesa en el "Prólogo" de Investigaciones lógicas, citando a Goethe, que "contra nada se es más severo que contra un error recientemente abandonado" (LU I: Prólogo, $7 /$ II/1: 23). 
de una determinada especie carece de sentido, porque entonces la misma proposición podría ser verdadera para una especie y falsa para otra. Ahora bien, el significado de las palabras "verdad" y "falsedad" hacen imposible que algo sea simultáneamente verdadero y falso. La tesis del relativismo antropológico contradice, pues, las palabras que usa para establecerse. ${ }^{26}$ Además, basar la verdad sobre la constitución psicológica es basarla sobre un hecho y darle, por tanto, el carácter de un hecho, que siempre es singular y temporal, mientras que la verdad es válida universalmente y en todo tiempo. El psicologismo es incapaz de justificar la validez universal de la verdad. Finalmente la relatividad de la verdad lleva consigo la relatividad del mundo, ya que el conocimiento y su objeto están ligados entre sí. Si la verdad se hace subjetiva, no habrá un mundo en cuanto tal, sino sólo un mundo para tal o cual especie de seres conscientes.

En su lucha contra el psicologismo, Husserl no se contenta con mostrar las consecuencias absurdas que de él se siguen. Saca también a relucir los prejuicios de los que nace. El más significativo de ellos es la confusión entre el acto psíquico y su contendio. El psicologista concibe los términos "proposición", "juicio", "prueba", "verdad", etc., como fenómenos psíquicos. Si así fuera, responde Husserl, las matemáticas puras serían una rama de la psicología. Pero por mucho que los conceptos matemáticos sean psicológicos en su origen, las leyes que por ellos se expresan no dependen de la constitución psíquica del hombre. Contar "uno", "dos", "tres" es un acto psíquico concreto que se da en el tiempo y el espacio, ahora y aquí; sin embargo los números 1, 2, 3 presentan un contenido no empírico, que desborda por completo el carácter fáctico y temporal del acto psíquico por el que se expresan. Ahora bien, es a ellos y no al acto de contar a los que se refiere la aritmética. La misma distinción vale para la lógica. Una cosa es el acto por el que yo enuncio el principio de identidad y otra el principio mismo, con su exigencia lógica de universalidad y necesidad. ${ }^{27}$

Para poner de relieve la confusión de planos existente en el punto de vista del psicologismo; Husserl aduce, como hemos ya apuntado, la distinción entre el acto psíquico individual del pensar (lo que más tarde denominará noesis) y el contenido objetivo del pensamiento (lo que denominará noema). Tomemos una sencilla proposición matemática, por ejemplo: $2 \times 2=4$. El contenido expresa una necesidad ideal y objetiva, y como tal independiente del acto real de pensarlo. La verdad de esta proposición no se rige por el pensar fáctico de una psique, sino que el pensar fáctico de toda psique debe regirse por ella. ¿De dónde viene la mismidad del noema, si la noesis es distinta? Esa identidad no puede provenir de la mente, sino del mismo

26 Cfr. LU 1: $\S \S 32-38,118-128 /$ IL/1: 109-117.

27 Cfr. LU I: $\S \S 44-48,170-182$ / IL/1: 147-155. 
objeto ideal. En todos estos casos nos hallamos ante una validez a priori y absoluta que no puede provenir del pensamiento, sino de su objeto. ${ }^{28}$

He aquí uno de los puntos cardinales de la fenomenología: el intento de fundamentar la ciencia a través de una contundente refutación del psicologismo, que considera la razón una cuestión cerebral y ve al hombre como organismo biológico. Desde este prisma psicologista el hombre queda reducido a las condiciones fácticas que lo han producido y, por tanto, el hombre no guarda ninguna relación con la verdad.

De ahí, como señala acertadamente San Martín, que el esfuerzo más persistente de Husserl se centre en el desvelamiento de la no facticidad del sujeto de la ciencia; en la demostración de que con un sujeto de hechos la ciencia no puede ser construida; en desvelar, en definitiva, que el hombre no es un hecho mundano, sino el lugar de la razón y de la verdad, la subjetividad transcendental. ${ }^{29}$

Husserl se sitúa en el horizonte de un sujeto que quiere fundamentar radicalmente desde sí mismo toda posible verdad y dar paso a la construcción de una filosofía como ciencia estricta y rigurosa, tal como manifiesta en su artículo de la revista Logos en 1910/1911.

Heidegger considera que el psicologismo no es un tema baladí para la filosofía dada su enorme capacidad de recuperación ante las diversas críticas que recibe desde el neokantismo y, sobre todo, desde las Investigaciones lógicas de Husserl. "Tan pronto como uno se aproxima a los problemas especiales de la lógica y trata de alcanzar una solución segura, se pone de manifiesto hasta qué punto prevalece todavía el modo de pensar psicologista, cuán enredados y multiformes son los caminos que una lógica pura tiene que sortear." 30 Precisamente, la exposición de las diversas teorías sobre el juicio llevada a cabo en la disertación irá encaminada, no sólo a rechazar el psicologismo, como a probar cuán preñadas están de sus presupuestos teóricos. Incluso podría decirse que el mismo hecho de exigir tal prueba encerraría un contrasentido, en caso de que la prueba fuese de tipo deductivo, pues para ella necesitaríamos premisas, las que a su vez tendrían que ser probadas, con lo que implicaríamos en el proceso a la misma lógica

28 De este modo, restablece Husserl el sentido de conocimiento como conocimiento de la verdad. Cuando yo enuncio una proposición verdadera lo hago en su esencia ideal, valedera para todos y para siempre. La verdad o es absoluta o no es verdad. He aquí la respuesta de Husserl a los psicologistas. Ellos quisieran hacerla relativa, dependiente del hombre que la piensa. La verdad, en cambio, es una e idéntica. "No está 'en algún lugar en el vacío', sino que es una unidad de validez en el reino intemporal de las ideas" (LU I: $\$ 39,136 / \mathrm{IL} / 1$ : 122).

29 San Martín (1987), p. 42. En este sentido, la fenomenología de Husserl nace y se desarrolla en el seno de la consideración de la crisis de la matemática y de la lógica, es decir, de las ciencias formales, y termina con la consideración de la crisis de las ciencias en general.

30 GA 1: 64. 
que estamos intentando probar. ${ }^{31}$ La realidad de la lógica, en lugar de ser probada, debería tan sólo ser puesta de manifiesto.

De ahí la insatisfacción de Heidegger ante la situación de las investigaciones lógicas del momento, presa de dos posiciones antagónicas y parciales: por un lado, la actitud psicologista; por otro, la actitud formalista. Ambas posiciones, insatisfactorias por su parcialidad, arrancarían de Kant: ${ }^{32}$ el formalismo de corte neokantiano significaría hipostasiar la lógica en un reino sin anclaje en el ser, en una actitud prototípicamente platónica que eleva las Ideas a entes metafísicos; ${ }^{33}$ en cambio, el psicologismo, a través de la interpretación de Schopenhauer y de Fries, habría desembocado en una naturalización de la conciencia, reduciendo las leyes lógicas a leyes empíricas del funcionamiento de la mente humana. Pues bien, sean cualesquiera los mecanismos psico-fisiológicos que producen la conciencia, ésta es, en su pureza originaria, un mero darse cuenta de algo: la conciencia es siempre y sólo "conciencia de", precisamente en cuanto puro darse cuenta de algo. El error principal que Heidegger, en boca de Husserl, reprocha al psicologismo se cifra en la naturalización de la conciencia, el haber convertido el mero momento de darme cuenta de algo en un sistema de mecanismos que a lo sumo podrían explicar cómo llego a darme cuenta, pero jamás me dirán en qué consiste el puro darme cuenta.

Para Heidegger, la pertinaz vigencia del prejuicio psicologista no es otra cosa que la manifestación de un problema mal planteado desde su raíz: el de la separación entre conocimiento y valoración. El conocimiento científico, absoluto, de validez universal, por un lado, y la esfera de los valores hipostasiados, por otro. Late en el fondo el rechazo a una concepción puramente contemplativa del conocimiento. Un rechazo a que el conocer sea entendido como un mirar o una simple presencia de algo, sin que el sujeto tome una postura activa frente a lo aprehendido. En cambio, para Heidegger, conocer es apreciar, valorar. Cualquier captación del ser no es, en ningún caso, pura actividad teórica, sino ante todo un comportamiento valorativo. ${ }^{34}$ Ese comportamiento irá adquiriendo en la época de maduración de su pensamiento tintes cada vez más prácticos, que en Ser y tiempo lo llevarán al reconocimento del cuidado como estructura fundamental del ser-ahí.

31 Cfr. García Gainza (1997), p. 20.

32 Cfr. GA 1: 19.

33 Cfr. GA 1: 24.

34 Vattimo ha señalado con acierto que en estos primeros trabajos de lógica hasta las tempranas lecciones de Friburgo se encuentra ya esbozado lo que va a ser una constante de la reflexión heideggeriana: el pensar el ser, cuyas raíces voluntaristas, es decir, no teóricas, aparecen insistentemente en este periodo. (Cfr. Vattimo (1986), p. 23.) 
Ahora bien, ¿qué aspectos de la lucha husserliana contra el psicologismo incorpora Heidegger a su propio planteamiento? Básicamente son dos: el primero, la comprensión de la diversidad de los ámbitos del ser; el segundo, la intencionalidad como estructura fundamental del fenómeno psíquico. El psicologista conoce las cosas por fuera y por dentro, en la conciencia, los procesos psíquicos. Heidegger hace suya la conclusión de Husserl de que las leyes lógico-matemáticas no son inductivas, sino a priori y su necesidad no es meramente psicológica, sino objetiva. El error psicologista nace del desconocimiento de la intencionalidad como propiedad fundamental de la conciencia. Por otra parte, la diversidad de los ámbitos del ser queda claramente establecida con la diferencia entre ser ideal y ser real. Esa diferencia se elabora en el ámbito de una defensa de las pretensiones de validez de la lógica frente a su relativización psicológica. La elaboración de una lógica pura precisa de una doctrina de las categorías que articule el ser en sus múltiples sentidos. Sólo así "podrá uno aproximarse a los problemas epistemológicos y estructurar el ámbito del 'ser' en sus distintos modos de realidad". 35

En el artículo, Nuevas investigaciones sobre lógica, se afirma que

de cara al reconocimiento de la esterilidad teórica del psicologismo resulta fundamental la distinción entre acto psíquico y contenido lógico, entre el acontecer real del pensamiento que transcurre en el tiempo y el sentido extratemporal, idéntico e ideal; en suma, la distinción entre lo que "es" y lo que tiene "validez" (GA 1: 22).

La meta de la ontología de Heidegger consiste en mantener la esfera del sentido lógico en un ámbito autonónomo y distinto de la realidad espaciotemporal óntica, tanto de los actos písquicos del juzgar como del mundo físico sobre el cual se emiten los juicios. Con esta diferencia ontológica entre ente lógico ideal y entes espacio-temporales reales se introduce Heidegger en una de la cuestiones básicas de la metafísica occidental.

Para el psicologismo la realidad efectiva psíquica, el ser real de lo psíquico, es la fuente de la que brota la legalidad del pensar. En consecuencia, también la verdad de un juicio se convierte en dependiente de la disposición psíquica en cada caso de tipo diferente. Lo que puede ser verdadero para un tipo, puede para otro ser falso. Contra ello aduce Husserl que los principios fundamentales del pensar no son leyes reales sino ideales, que la verdad no es relativa sino absoluta, constituyendo una unidad ideal frente a la pluralidad de individuos y vivencias reales. El psicologismo ignora la diferencia

35 GA 1: 186. Una empresa que el mismo Heidegger emprende en su tesis de habilitación sobre Duns Escoto, sobre la que volveremos más adelante en este mismo artículo. 
fundamental entre el ser real de la decisión judicativa y la validez ideal del contenido enjuiciado. ${ }^{36}$ Como señalará más tarde Heidegger, la equivocación principal del psicologismo es "ignorar la diferencia de una diversidad fundamental en el ser del ente". ${ }^{37}$ Desde la pluralidad de las maneras de ser, el psicologismo sólo conoce un modo de ser: el del ser real de lo psíquico. $Y$ aunque para Heidegger siga siendo insuficiente la distinción husserliana entre ideal y real, se vislumbra en ella una senda hacia la comprensión de que "la lógica está construida sobre un fondo ontológico", ${ }^{38}$ que deja abierta la cuestión del sentido del ser en general.

La lógica tradicional se ve limitada por su excesiva orientación teórica. La lógica filosófica tiene por objeto ofrecer un punto de partida más radical: "preguntar por lo verdadero en sentido originario y propio". ${ }^{39}$ Esto significa retrotraer el comportamiento lógico del enunciar y juzgar hacia las estructuras ontológicas fundamentales que han quedado veladas en la lógica tradicional. Heidegger se pregunta cómo el contenido lógico, esto es, el sentido, está relacionado con los actos de pensamiento y, eventualmente, con el ente pensante que es el ser humano. ${ }^{40}$ De hecho, en Ser y tiempo se afirmará que "la lógica tiene sus raíces en la analítica existenciaria del ser-ahi". ${ }^{41}$ Precisamente, ésta es la tarea que emprende Heidegger en sus primeros trabajos, que culminan en una afirmación radical del valor originario de la vida humana, y que en el curso de 1925-1926, Lógica. La pregunta por la verdad, lo llevarán a sostener que la lógica sólo es comprensible desde la temporalidad extática del ser-ahí.

De momento, la esfera de validez de la lógica pura, que se resiste a todas las tentaciones de relativización por parte de la biología y la psicología, se convierte en el lugar donde ubicar el valor trascendente de la vida, pues Heidegger cree que con la lógica puede alcanzar un nivel de validez supraindividual que permita preservar la realidad objetiva del espíritu. El espíritu no puede ser una mera producción mental. Aquí se ve cómo sus primeros pasos en el camino de la filosofía se orientan por un realismo crítico, que trata de evitar la caída en el materialismo y la ascensión a los cielos del idealismo subjetivo.

En definitiva, si bien es cierto que en sus primeros trabajos sobre lógica Heidegger aparece tomando una clara y explícita posición antipsicologista,

36 Cfr. Hermann (1997) pp. 79 s.

37 GA 1: 50. Una observación realizada a propósito de la recensión de 1914 al libro de Charles Sentroul, Kant y Aristóteles.

38 GA 1: 50.

39 GA 1: 12.

40 Cfr. Mohanty (1988), p. 110.

41 SuZ: $\S 33,160 /$ SyT: 179. 
defendiendo el carácter irreductible de lo lógico en la línea de la escuela neokantiana y la fenomenología, no lo es menos que está mostrando continuamente su discrepancia ante un tratamiento en exceso formalista de la lógica. La pura lógica no tiene nada que ver con la psicología, cuya naturalización de la conciencia y de las leyes lógicas acaba de criticar, pero tampoco se inclina por una pretendida pureza formal. ${ }^{42}$ Este esfuerzo por localizar los dos polos del problema de la lógica se halla presente en toda la disertación. Por una parte, se confirma que el psicologismo, al equiparar las leyes lógicas a las empíricas, ha colocado la pregunta por el objeto de la lógica en un terreno que no le corresponde: el de la génesis del pensamiento en el contexto de las operaciones mentales. Por otra parte, Heidegger se esfuerza por distanciarse del rigor formal en busca de un trasfondo extralógico que, irreductible a la pura formalización, sirva de base sólida a la lógica. Se confirma la imposibilidad de que la lógica pueda hacer frente desde su esfera de validez a su propia fundamentación.

\section{La teoría del juicio}

\subsection{Observaciones críticas a las teorías psicologistas del juicio}

En la introducción de la tesis doctoral, La doctrina del juicio en el psicologismo (1913), Heidegger reconoce nuevamente que el auge de la investigación psicológica resulta un hecho innegable a finales del siglo xix. Sus consecuencias ya quedaron retratadas: una naturalización de la conciencia y la subsiguiente relativización de la validez de los juicios lógicos. No obstante, merced a los trabajos de la escuela neokantiana y de Husserl se ha logrado rehabilitar la autonomía de la lógica. En este sentido, para evitar futuros planteamientos de corte psicologista se propone un previo y detenido análisis de las teorías del juicio imperantes en el panorama filosófico contemporáneo del joven Heidegger. Y ipor qué convertir a la teoría del juicio en objetọ de investigación? Heidegger responde que es precisamente el juicio, considerado una pieza esencial del edificio de la lógica, el que permite distinguir con mayor nitidez el ámbito psíquico del lógico. Desde este punto de vista, la tesis doctoral se divide en dos grandes partes. En la primera se analizan los diferentes tipos de psicologismo presentes en las teorías del juicio de

42 Cfr. GA 1: 19. Además, que en la lógica interviene el aspecto material es algo que al joven doctorando le parece indiscutible después de las investigaciones de Emil Lask. La naturaleza de ese material queda, de momento, sin esclarecer. En el apartado 3.2 de este trabajo se incidirá en la importancia que cobra el principio de la determinación material de la forma de Lask en el desarrollo del pensamiento de Heidegger. 
Wilhelm Wundt, Heinrich Maier, Franz Brentano y Theodor Lipps. ${ }^{43}$ En la segunda se sopesan los resultados obtenidos del análisis crítico de la primera parte y se esbozan los rasgos generales de una teoría del juicio pura.

La exposición crítica de las mencionadas doctrinas del juicio arranca con Wilhelm Wundt quien aborda la cuestión del origen del juicio. ${ }^{44}$ Wundt realiza una revisión preliminar de las teorías tanto subjetivas como objetivas del juicio y llega a la conclusión siguiente: tanto la concepción subjetiva del juicio, que entiende éste como una forma de relacionar y separar conceptos, como la concepción objetiva, que ve en el juicio un modo de pensar que concuerda con la ordenación real de las cosas, conciben el juicio como un elemento que unifica conceptos o representaciones. Wundt, en cambio, afirma que el juicio no unifica conceptos elaborados independientemente, sino que primero segrega juicios a partir de una representación unitaria. Para él, la función propia del juicio consiste en descomponer un pensamiento en sus componentes conceptuales constituivos. ${ }^{45}$ Sin embargo, Heidegger muestra que la teoría de Wundt no se cumple en el caso de los juicios impersonales; es decir, aquellos juicios cuyo sujeto está indeterminado. Tomemos, por ejemplo, el juicio "relampaguea" ("es blitzt"). En él se nos hace patente una representación global del rayo iluminado. Podríamos descomponer este juicio, según la propuesta de Wundt, en los elementos "es" y "blitzen". Pero qué significa este "ello" ("es") como materia de la representación, se interroga Heidegger. Simplemente no se puede aplicar la función analítica de descomposición a los juicios impersonales. ${ }^{46}$

La crítica de Heidegger, empero, se encamina en otra dirección. Desde la óptića psicológica, parece que el pensamiento humano se dirige primero hacia el objeto y sólo más tarde vuelve sobre la naturaleza del sujeto pensante. Y ¿cuáles son las características propias del pensar? Pensar es, ante todo, una actividad subjetiva; es más, es una actividad autoconsciente y relacional que emerge de la apercepción. Ahora bien, ¿la investigación de Wundt es relevante para la lógica? Heidegger responde con una negativa rotunda, pues resulta totalmente erróneo aplicar los métodos de análisis psicológicos a las definiciones de la lógica: si concebimos el juicio de la lógica como un

43 En el marco de una estructura expositiva prototípicamente académica cada una de estas teorías se examina a partir de la definición general que se da del juicio y luego se contrasta su validez en los casos de juicios negativos, impersonales, hipotéticos y existenciales. Así, cada uno de los primeros cuatro capítulos de la tesis doctoral presenta por separado cada una de las teorías defendidas por los cuatro autores mencionados.

44 Los primeros cuatro capítulos de la tesis doctoral se dividen formalmente siempre en dos apartados: uno de exposición de la teoría de cada autor y otro de valoración crítica.

45 Cfr. GA 1: 66-67.

46 Cfr. GA 1: 78. 
proceso psíquico seguimos operando en el marco del psicologismo. ${ }^{47}$ Ésta es precisamente la consecuencia de comprender la apercepción como una forma de actividad subjetiva. El análisis psicológico no sirve de fundamento para la lógica, ya que la lógica tiene por objeto estudiar el carácter normativo del pensar y no las vivencias psíquicas.

En el capítulo segundo, Heidegger somete a consideración la teoría del juicio de Heinrich Maier, que se propone descubrir cuáles son los diferentes actos que componen el juicio. De entrada, se constata el hecho de que los intereses de la psicología, y en mayor grado los de la lógica, se han concentrado casi exclusivamente en la actividad cognitiva y epistemológica de la vida del espíritu. Maier, por el contrario, se decanta con preferencia por los aspectos prácticos y emocionales que rodean al pensamiento. El pensamiento discurre tanto en el ámbito imaginativo, lo que Maier denomina "fantasía afectiva", como en el mundo de los fines, de las normas, de los valores y de los bienes y, que de forma espontánea, nos sobrevienen en la contemplación estética, la creencia religiosa, el derecho y la moral..$^{48}$

Esta actividad pensante volitiva, sin embargo, ya siempre presupone cierto grado de representaciones que el espíritu genera a través de la experiencia y que, por primera vez, alcanzan independencia psíquica en el momento de llamar la atención sobre las mismas. Este interés activa un proceso que transforma lo simplemente dado en la conciencia en representaciones emocionales o epistemológicas. Precisamente, el acto que facilita este tránsito de lo dado en la conciencia a la representación epistemológica es el juicio. De ahí que un estudio de la estructura lógica de las representaciones emocionales no dispense de un análisis de las funciones elementales del juicio. ${ }^{49}$

Desde Aristóteles, la lógica tradicional ha basado el estudio del juicio en los siguientes dos supuestos: por un lado, otorga primacía a los enunciados proposicionales qua entidades gramaticales, que - de acuerdo con Maiercaen bajo la estructura de sujeto, predicado y cópula; por otro lado, se asienta en la creencia de que las representaciones nunca pueden ser por sí mismas verdaderas o falsas, sino que los predicados de "verdad" y "falsedad" únicamente se pueden aplicar a la relación entre representaciones. ${ }^{50} \mathrm{En}$ contra de esta postura, Maier sostiene que el juicio, en su forma básica, no se reduce a una mera conexión de representaciones. El juicio consiste en un acto de presentación que, posteriormente, es transformado en juicio

47 Cfr. GA 1: 84.
48 Cfr. GA 1: 91.
49 Cfr. GA 1: 92.
50 Cfr. GA 1: 93 
lógico por medio de un acto de objetivación. ${ }^{51}$ En este sentido, el acto de objetivación es un tipo de acto interpretativo en el que confluyen otros dos momentos lógicos: el contenido representacional y el contenido de realidad. ${ }^{52}$

Obviamente, el enfoque que adopta Maier es psicológico y genético, no lógico. Maier se vuelca sobre el acto de juzgar y se olvida del contenido del juicio como tal. Y eso significa permanecer anclado en el psicologismo: una teoría del juicio que contempla éste a modo de una realización de procesos lógicos reduce los actos fundamentales del pensamiento a funciones volitivas y emocionales subjetivas y, por tanto, relativas y cambiantes. ${ }^{53} \mathrm{En}$ conclusión, los resultados sobre la investigación de las vivencias psicológicas resultan estériles para la lógica, ya que ésta se despreocupa de las vivencias como tales y se concentra en el contenido objetivo del juicio.

También Franz Brentano rechaza la idea de que el juicio sea un conjunto de representaciones. Hablamos de representación siempre que "algo se nos manifiesta". Cuando oímos algo, nos representamos un sonido; cuando vemos, un color. En Brentano, no obstante, el contenido de la representación, el noema, queda relegado en favor del comportamiento psíquico del acto de representar, la noesis. El juicio, pues, encarna un tipo particular entre los fenómenos psíquicos, como el recuerdo, la opinión, la convicción o la duda, y obedece a la estructura intencional de los mismos; esto es, el juicio, al igual que los restantes fenómenos psíquicos, se caracteriza por el "estar referido a" un objeto. ${ }^{54}$

Ahora bien, el contenido del juicio, aquello que es reconocido o rechazado, no suscita la atención de Brentano. El acto de reconocimiento como tal, objeta el joven Heidegger, no resulta de interés para la lógica. Cuando, por ejemplo, se afirma que $\mathrm{a}^{\circ}>\mathrm{b}$, si $\mathrm{a}=5 \mathrm{yb}=3$, lo que es reconocido no es la relación "mayor que", sino la relación de validez. Un valor que subsiste independientemente de cualquier reconocimiento. ${ }^{55}$ Precisamente, esta inclinación de Brentano hacia la conducta psíquica dificulta el reconocimiento de la validez universal del conocimiento y sumerge su análisis en el psicologismo.

Y, en el cuarto capitulo, se sopesan los esfuerzos que Theodor Lipps dedica al estudio del proceso de formación del juicio. En el juicio, a diferencia de la mera apercepción, interviene un tipo de reconocimiento peculiar en el que somos conscientes de la validez y de la verdad de los objetos represen-

51 Cfr. Mohanty (1988), p. 117

52 Cfr. GA 1: 96.

53 Cfr. GA 1: 105-112.

54 Cfr. GA 1: $115 \mathrm{~s}$.

55 Cfr. Mohanty (1988), pp. 118-119. 
tados. ${ }^{56} \mathrm{Y}$ a esta conciencia de validez y de verdad se suma la conciencia del objeto que nos permite diferenciar entre el contenido y el objeto: el contenido es percibido o representado, mientras que el objeto es pensado y pretende ser reconocido. Ahora bien, la exigencia de reconocimiento es un concepto lógico que se mueve en el ámbito de la validez. ${ }^{57}$ Esto significa que el objeto, que sólo es objeto en cuanto pensado, es ajeno a cualquier evento psíquico. En otras palabras, el juicio de la lógica es trascendente respecto a las determinaciones espacio-temporales de las vivencias psíquicas.

La conciencia ya no se dirige con su pretensión de reconocimiento a los sucesos psíquicos, al discurrir de representaciones, sino a aquello que es pensado en los contenidos representacionales (esto es, el objeto). (GA 1: 150)

Este mundo de los objetos se halla fuera del ámbito de lo psíquico y en él, por tanto, opera el yo puro que remite a la conciencia en general. Del mismo modo la universalidad de las leyes del pensamiento no se alcanza por medio de los procedimientos de una psicología empírica que describa las vivencias de conciencia de un yo real y efectivo. En definitiva, las normas lógicas no informan sobre hechos psíquicos. ${ }^{58}$

Mas Lipps ve "la esencia del juicio lógico en el acto de reconocimiento". 59 Reconocer es, en todo momento, cuestión del individuo; un hecho, por tanto, determinado temporalmente. De ahí que la teoría del juicio de Lipps, apunta Heidegger, no quede por entero a salvo de las trampas del psicologismo. Heidegger concluye que la lógica no tiene nada que ver con el modo en que el individuo se comporta mientras juzga. Por el contrario, "al lógico sólo le interesa el sentido del juicio; el proceso que permite formular un juicio carece de significado para los propósitos de la lógica". ${ }^{60}$

La exposición crítica de las distintas teorías del juicio ha puesto de manifiesto que el psicologismo carece de aplicación en la lógica; es más, desconoce absolutamente la naturaleza del objeto lógico. ${ }^{61}$ Estas doctrinas comparten una concepción común del juicio: el juicio es una realidad psíquica, un proceso psíquico, un acto, una actividad que se inserta en el conjunto de la realidad psíquica. ${ }^{62}$ La psicología estudia las diversas sensaciones simples y complejas a partir de la cuales se construyen las realidades psíquicas. En el juicio, en cambio, nos hallamos ante representaciones. Y llegado a

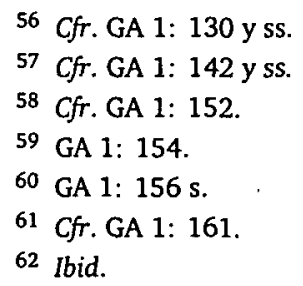


este punto Heidegger se plantea el siguiente interrogante: ¿cómo se llega de los elementos psíquicos originarios a la formación de representaciones en el juicio? ${ }^{63}$ El problema del juicio, insiste Heidegger, no encuentra una solución en la esfera de lo psíquico, ya que todo aquello que reviste el carácter del discurrir temporal permanece indiferente al ámbito de validez de la lógica.

\subsection{La cuestión de la validez}

La revisión de las teorías de Wundt, Maier, Brentano y Lipps pone a Heidegger sobre la pista de una serie de problemas que atañen directamente a una doctrina del juicio: las múltiples y taimadas formas que puede adoptar el prejuicio psicologista en la lógica, la limitación de un enfoque todavía ligado a una concepción cartesiana del juicio como acto epistémico de un sujeto pensante y la esterilidad de un tratamiento excesivamente formal de la naturaleza de la lógica. La refutación del psicologismo ya puso de manifiesto que éste ha prescindido de cualquier análisis del contenido noemático del juicio para concentrarse casi exclusivamente en el acto psíquico del juzgar. "El psicologismo desconoce el objeto lógico [.. .]; un desconocimiento que no es un simple mal entendido, sino un genuino no-entender." 64 De ahí el interés de Heidegger por forjar una teoría de la lógica depurada de todo vestigio psicologista.

En esta línea, el quinto y último capítulo de la tesis, pretende sentar las bases de esa nueva doctrina lógica del juicio. Empieza por distinguir cuatro tipos de realidad diferentes e irreductibles entre sí: realidad física, psíquica, matématica y lógica. En una sorprendente anticipación de su posterior terminología, Heidegger dice que el sentido lógico es un modo de existencia que, al igual que los existenciarios, no puede explicarse por nada más.

¿Cuál es el sentido del sentido? ¿Tiene algún sentido interrogar por ello? [...] Quizás nos hallamos aquí ante algo último e irreductible que excluye toda clarificación ulterior. (GA 1: 171)

Al igual que en la Sexta Investigación de Husserl, se argumenta que uno sólo puede mostrar y describir el sentido a través de actos evidentes de intuición categorial.

En cualquier caso, si el sentido lógico simboliza un tipo de realidad peculiar, entonces no cabe decir de él que "existe" o que "es", tan sólo que "es válido". El sentido lógico, pues, se mueve en el ámbito de la validez. ${ }^{65}$ En

${ }^{63}$ Cfr. GA 1: 162.

64 GA 1: 161.

${ }^{65}$ Cfr. GA 1: 170. 
primer lugar, validez significa la forma de idealidad que reviste el sentido de un juicio, esto es, no "existe" en la realidad del tiempo y del espacio. En segundo lugar, designa la validez que tiene el sentido predicativo de un juicio para el sujeto lógico. En la proposición "La tapa del libro es amarilla", el predicado "ser amarillo" resulta válido para "la tapa del libro". Pero este "es", se apresura a señalar Heidegger, no encierra ningún valor existencial, no tiene ningún sentido verbal activo; únicamente denota la estructura relacional estática que se da entre el objeto y un determinado contenido significativo.

La cópula, por tanto, no guarda ninguna relación necesaria con la forma verbal abstracta "es"; representa algo eminentemente lógico cuya forma de realidad es precisamente la validez. (GA 1: 178-179).

Y la validez de un juicio, como ya afirmara Husserl en las Investigaciones lógicas, obedece al criterio de la correspondencia entre lo mentado y lo dado. ${ }^{66}$ El juicio es el lugar primordial de la verdad. El proceso psíquico del juzgar sólo es verdad en un sentido derivado. ¿Realmente puede decirse de un proceso que sea verdadero o falso? Un proceso 'es' o 'no es', nada más. En cambio, el contenido representacional es lo auténticamente verdadero, aquello que denominamos sentido. En sus años de formación académica, Heidegger se mantiene alerta ante cualquier atisbo de relativismo psicologista. Uno debe mantenerse a distancia del rumbo de las epistemologías psíquicas, físicas o prácticas y adentrarse en la ruta de una lógica pura, donde la categoría de la validez actúa de condición transcendental del conocimiento de los entes.

De este modo, se va dibujando en el joven Heidegger una ontología consistente en mantener la esfera del sentido lógico como un ámbito autónomo, distinto de la realidad espacio-temporal óntica. En su examen acerca del sentido temporal del juicio insiste en la diferencia onto-lógica entre la validez atemporal del sentido y la existencia espacio-temporal de los entes psico-físicos. Siguiendo a Bergson, Heidegger describe el aquí y el ahora del acto mismo de realización de un juicio en términos de la corriente fluctuante de la conciencia. ${ }^{67}$ Es una actividad en la que los actos, siempre diferentes y cambiantes, se suceden constantemente durante una duración de tiempo particular y en la que "la misma situación psíquica de la conciencia nunca se puede repetir". ${ }^{68}$ En cambio, el sentido del juicio es atemporal, idéntico, ideal, es 'un fenómeno 'estático', situado más allá de toda evolución y 
transformación y que, por tanto, no llega a ser, sino que tiene validez". ${ }^{69} \mathrm{El}$ sentido no se ve afectado por el tiempo de su referente físico. Es más, en medio del incesante fluir psíquico hay algo que permanece como un factor constante.

Heidegger vuelve a ejemplificar el carácter no-situacional del sentido de la mano del enunciado "La tapa del libro es amarilla". En un primer momento y de modo casi irreflexivo uno efectúa ese juicio mientras está sentado en su estudio; en otra ocasión se llega al mismo comparando arbitrariamente los colores de diferentes tapas entre sí; a veces la proposición se realiza a instancias de la pregunta de un amigo acerca del color de las tapas del libro. Los ejemplos se pueden multiplicar, pero "a la hora de emitir un juicio hallo en todas estas 'modificaciones de la conciencia' un factor constante en cada acto de juzgar; en cada momento quiero decir: 'La tapa del libro es amarilla' ".70 Únicamente resta la posibilidad de colocar el sentido del juicio fuera del devenir de lo psíquico; de lo contrario, el juicio sólo sería verdadero el tiempo que durara la actividad misma de juzgar. Una contingencia que no tiene cabida en el concepto de verdad. Es cierto que las circunstancias en las que digo 'La tapa del libro es amarilla' pueden variar unas de otras. Sin embargo, indistintamente de ser motivadas por la comparación o por la pregunta de un amigo, el juicio transmite el mismo sentido noemático.

Con la mencionada diferencia ontológica entre validez atemporal y discurrir temporal de los entes, Heidegger se instala en la arena de una de las principales cuestiones de la metafísica occidental. ${ }^{71}$ A tenor de la opinión de Gadamer, se trata de hallar el punto de encuentro entre lo intemporal, inmutable y universal con lo cambiante e histórico. ${ }^{72} \mathrm{El}$ mismo Heidegger confirma esa hipótesis a propósito de una reseña al libro de Nikolai Bubnoff, Temporalidad y atemporalidad, publicada en 1913 y en la que se plantea la cuestión todavía vigente desde Parménides y Heráclito de cómo salvar el absimo existente entre la realidad intemporal del pensamiento abstracto y la realidad temporal de la percepción sensible. ${ }^{73}$ Unas veces ese abismo adopta la forma de la clásica oposición realismo-idealismo, si bien permanece sin resolver el problema platónico de la participación, de la conexión entre la realidad atemporal del sentido y la realidad temporal de los objetos. Pero otras veces, como sucede en la disertación, las fuerzas se concentran en localizar un punto de encuentro entre ambos planos. Tradicionalmente se sitúa en el juicio. En el camino abierto por Brentano y Lipps hallamos

69 GA 1: 179.

70 GA 1: 167-168.

71 Cfr. Buren (1994), p. 65.

72 Cfr. Gadamer (1983), pp. 169 ss.

${ }^{73}$ Cfr. GA 1: 46. 
la referencia a un sujeto o a una conciencia, cuya naturaleza queda todavía por determinar. De entrada, Heidegger se apresura a anunciar que tal conciencia no es equiparable ni al sujeto transcendental de la filosofía neokantiana ni a la conciencia naturalizada del psicologismo. Los resultados de las Investigaciones lógicas de Husserl, que impregnan buena parte de las observaciones de Heidegger, parecen ofrecer una solución al romper con el hechizo psicologista y posibilitar un esclarecimiento de la lógica.

El mismo Heidegger reconoce en la introducción de su disertación la capital aportación de Husserl a este campo de estudio. Pero aceptar ese reconocimiento sin más supondría que Heidegger se aproxima a la fenomenología por razones meramente metódicas y no por el asunto mismo tratado. ${ }^{74}$ ¿Y cuál es ese asunto? El lugar de inserción de la validez universal de la verdad y las representaciones de la conciencia temporal del sujeto. Que esta inserción se efectúe a través de la síntesis judicativa, según la doctrina general de toda lógica, ofrece una respuesta insatisfactoria e inadecuada. Heidegger pretende retroceder hasta una zona vedada por la autoridad de Rickert, hasta la Wahrnehmung, hasta una fenomenología de la intuición y de las representaciones sobre las que ya estaban trabajando Husserl y Lask. ${ }^{75}$ Siguiendo los pasos de Lask, sobre quien volveremos más detalladamente en el próximo apartado, descubre indicios metafísicos en el misterio de la validez, en la esfera de la pura logicidad que resiste todas las tentativas de relativización de la biología y de la psicología. No obstante, en estos primeros años todavía no queda clara la relación entre la lógica y el sujeto. Con la lógica cree poder alcanzar una instancia de validez supraindividual, que le permite seguir creyendo en la realidad objetiva del espíritu. Pero simultáneamente desea reconocer la realidad independiente del mundo exterior, que no debe convertirse en la quimera de la subjetividad. Heidegger procura evitar ambas posturas: precipitarse en el materialismo y caer en el idealismo subjetivo. De ahí que sus primeros esbozos filosóficos se encaucen en la dirección de un realismo crítico que apuesta por la posibilidad de un espíritu objetivo. ${ }^{76}$

La solución ontológica a este conflicto pasa en esta fase de juventud por mantener la prioridad atemporal de la validez como fundamento del sentido de la experiencia histórica. Independientemente de que el sentido esté inmerso en una experiencia temporal, e incluso en una cosmovisión cultural, existen dos esferas ontológicamente heterogéneas. En la línea de un análisis fenomenológico a la usanża husserliana, los aspectos temporales

76 Cfr. Safranski (1994), pp. 56-57. 
han de suspenderse y ser sometidos a una reducción eidética que extraiga el sentido atemporal de los hechos históricos.

Aun cuando los momentos religiosos, políticos y, en el sentido más restringido, culturales de una época resultan indispensables para la comprensión de la génesis y del condicionamiento histórico de una filosofía, se puede abstraer de estos momentos en nombre del puro interés filosófico. El tiempo, entendido aquí como categoría histórica, es suspendido. [...] La historia de la filosofía mantiene una relación esencial con la filosofía si y sólo si deja de ser historia, ciencia de hechos y se proyecta en la pura sistemática filosófica. (GA 1: 196-197)

El estatismo de la lógica tiene que entrar en una relación tensa con una realidad temporalmente dinámica y cambiante. Heidegger explora este tema mediante el ejemplo de un problema que será importante para su filosofía posterior. Se trata del problema de la nada. Investiga la negación en el acto del juicio. Podemos decir que "la tapa del libro no es amarilla". Este "no" significa que una determinada propiedad a lo que nos referimos no se da: falta el amarillo de la tapa. A partir del faltar, del "no", puede abstraerse luego una "nada", si bien como mera cosa pensada. ${ }^{77}$ Por tanto, esa "nada" se da solamente en el acto del juicio, y no en la realidad.

En la conferencia “¿Qué es metafísica?", de 1929, Heidegger resumirá en la experiencia de la nada el origen de toda metafísica. La nada sitúa el mundo entero del ente en un cuestionable y angustiante estado de misterio. ${ }^{78}$ $\mathrm{El}$ joven Heidegger conoce indudablemente este estado de ánimo, pero todavía no lo asume en su filosofía. Todavía respira la atmósfera académica y se atiene al principio de que la "nada" se encuentra solamente en el juicio, pero no en la realidad. En su tratamiento del juicio impersonal, que late en las oraciones gramaticales carentes de sujeto, se pone de manifiesto lo lejos que aún se encuentra de los aspectos angustiantes de la realidad. Decimos, "relampaguea" (es blitzt). "¿Qué significa esto? ¿Quiero enunciar una propiedad, un estado momentáneo, que se refiere a un misterioso 'ello' (es), o bien el juicio tiene un sentido completamente distinto?"79 ¿Quién o qué es este "ello" que relampaguea? Heidegger escoge el ejemplo de "retumba" (es kracht) y escribe:

$\mathrm{Si}$, por ejemplo, en unas maniobras me apresuro con mi amigo para alcanzar una batería que adelanta rápidamente en posición de fuego y, en el momento

77 Cfr. Safranski (1994), p. 62. Precisamente este intento de rehabilitar los juicios negativos cumplirá un papel decisivo en sus lecciones de Marbrugo de 1925-1926, Lógica. La pregunta por la verdad, en las que mantendrá que el juicio es el lugar tanto de la verdad como de la falsedad.

${ }^{78}$ Cfr. GA 9: 106 ss.

79 GA 1: 185. 
en que oímos el estallido de los disparos, digo: "Date prisa, que ya retumba", entonces es enteramente determinado lo que retumba; el sentido del juicio se cifra en el retumbar, en el producirse (ya) ahora. ${ }^{80}$

¿No remite esto al estar descubierto del ente, a la alétheia como condición previa de la verdad predicativa?

El estudio del juicio impersonal muestra que ni las investigaciones psicológicas, ni la determinación de la significación de las palabras pueden expresar el contenido del juicio. Para ello es preciso conocer y comprender el contexto de la acción. He ahí el tema del mundo de la vida cotidiana que Heidegger habrá de escrutar intensa y prolíficamente a partir de sus lecciones de 1919 como escenario de su pregunta por el ser. En los parámetros en los que se desarrollan sus primeros trabajos de juventud, $L a$ doctrina del juicio en el psicologismo (1913) y La doctrina de las categorías y del significado en Duns Escoto (1915), se observa un gradual distanciamiento de una lógica matemática ligada al cálculo de proposiciones en favor de una lógica filosófica que va a situar el fundamento de la lógica en el sustrato vivencial de la existencia humana. Con todo, el joven Heidegger no se deja llevar por la fascinación en boga del tema de la vida y finaliza su tesis doctoral apuntando hacia la necesidad de una lógica pura, con cuya ayuda afronta los problemas epistemológicos y estructura los ámbitos del ser. Y esta actitud soprende aún más, teniendo en cuenta que en esta corriente vitalista aparecen motivos que ocuparán poco después un lugar importante en la filosofía de Heidegger: la disolución del sujeto epistemológico, la historización del espíritu, la experiencia del tiempo o el arte como lugar de la verdad.

\section{La fundamentación de la lógica}

El problema de cómo el modo de realidad efectiva del sentido lógico venga desgajado del ser del ente remite a la tarea última y suprema de la filosofía: articular el ámbito del ser en sus diversas maneras de manifestación. Una tarea que pasa por una teoría de las categorías y del significado, encargada de delimitar los distintos ámbitos de la realidad en zonas categorialmente irreductibles entre sí. Con ello retomamos directamente el hilo conductor de la tesis de habilitación de Heidegger (3.1). En ella se nos mostrará que las formas categoriales que usa el intelecto no puras entidades vacías, sino que están necesitadas de plenificación. Un planteamiento en la línea del principio de la determinación material de la forma de Emil Lask (3.2), que pondrá a Heidegger sobre la pista de la vida humana como fundamento útlimo de la lógica (3.3). 


\subsection{La doctrina de las categorías y del significado}

En el escrito de habilitación, La doctrina de las categorías y del significado en Duns Escoto (1915), volvemos a encontrar a un Heidegger preocupado por los problemas de la matemática y la cuestión de la fundamentación de la lógica. A partir de este objetivo, se inicia un estudio crítico de la doctrina escolástico-medieval de la categorías, en la órbita de una fiel adhesión al neokantismo de su director de tesis, Heinrich Rickert, y a la fenomenología de su futuro mentor, Edmund Husserl. En este sentido, poco importa que uno de los principales textos de Duns Escoto examinados por Heidegger, la Grammatica speculativa sive de modis significandi, fuera en realidad redactado por el escotista Thomas de Erfurt, ya que Heidegger lleva a cabo un tratamiento histórico del problema más que una exégesis dirigida a la mens auctoris.

El trabajo sobre Duns Escoto responde a algo más que a un mero interés de anticuario. Obedece a una concepción de la historia de la filosofía entendida como aparición recurrente de problemas, antes que a una superación de errores pasados en aras del progreso de la Verdad. ${ }^{81}$ En este contexto merece la pena recordar algunas palabras del currículum escrito por el puño y letra de Heidegger en 1915, donde se expresa con suma claridad la actitud filosófica del candidato a la habilitación. Se trata de un testimonio directo que no ha sido deformado ni interpretado posteriormente y que también sirve para reconstruir pasajes de su andadura intelectual y universitaria.

El estudio de Fichte y Hegel, el profundo análisis de la obra de Rickert, Límites de la formación de conceptos en las ciencias de la naturaleza, y las investigaciones de Dilthey tuvieron como consecuencia que mi aversión por la historia, alimentada por mi predilección por las matemáticas, se derrumbara por completo. Me di cuenta de que la filosofía no puede orientarse unilateralmente ni según las matemáticas y las ciencias de la naturaleza ni según la historia, pero que esta última, en su calidad de historia del espíritu, puede enriquecer incomparablemente más a los filósofos. Este incipiente, pero creciente interés histórico, me facilitó el estudio de la filosofía medieval, absolutamente necesario para un profundo conocimiento de la escolástica. Para mí, tal estudio consistía no tanto en una descripción de las relaciones históricas entre los diferentes pensadores cuanto, principalmente, en una comprensión explicativa del contenido teórico de su filosofía con los medios de la filosofía moderna. Así nació mi investigación sobre la doctrina de las categorías y el significado de Duns Escoto, que hizo madurar en mí el plan de una presentación global de la lógica y la psicología

81 Cfr. GA 1: 193-206. La cuestión de la Problemgeschichte es un principio metodológico que Heidegger invocará luego en las primeras sesiones de todos sus cursos académicos de la primera etapa de Friburgo y Marburgo. Un principio que, al fin y al cabo, se inspira en el lema husserliano de "a las cosas mismas". 
medievales a la luz de la fenomenología moderna, contemplando también la posición histórica de los distintos pensadores medievales [Curriculum vitae]. ${ }^{82}$

Tal como reconoce el medievalista Martin Grabmann, Heidegger renuncia de un buien principio a un enfoque genético y opta por una interpretación de los textos de Escoto en el lenguaje y la terminología de los autores que ya había estudiado en su tesis doctoral: Lotze, Windelband, Rickert, Lask o Husserl. ${ }^{83}$ Pero iqué busca Heidegger en el pensamiento medieval, en concreto, en Duns Escoto? Afirma que la escolástica medieval y su doctrina de la intencionalidad plasman una fenomenología noemáticamente orientada hacia los actos psíquicos del sujeto humano, si bien no aplica una explícita reducción fenomenológica. En Duns Escoto ya cabría hablar de la distinción fenomenológica entre una prima intentio, la actitud naturalista centrada en los objetos de las percepciones y de los pensamientos, y una secunda intentio, la atención sobre el contenido mismo de esas percepciones y representaciones.

Una vez delimitado el propósito del trabajo, la primera parte de la habilitación da paso al análisis de aquellas categorías fundamentales que nos permiten aprehender en primera instancia la realidad. En el esquema de Duns Escoto, una metaphysica generalis de los trascendentia del ens, unum, verum y bonum. Pero entre estas categorías hay una que sobresale por encima de las demás, a saber: el ens. A la luz de esta categoría determinamos e iluminamos cualquier ente particular en tanto que ente, en tanto que un objeto presente a nosotros. En un lenguaje henchido de resonancias transcendentales, Heidegger interpreta el ens en términos de la objetividad de los objetos de experiencia.

Primum objectum est ens ut commune omnibus. Este ens está dado en todo objeto de conocimiento [...]. Ens no significa otra cosa que la condición de posibilidad del conocimiento de los objetos en general. (GA 1: 214)

Los restantes trascendentia, que también ejercen de condiciones universales de posibilidad de la experiencia de los objetos, son convertibles con el ens. Éste representa la "categoría de las categorías", el "elemento primario", la "categoría primera". ${ }^{84}$ Todas las restantes categorías, bien los otros trans-

82 En Ott (1992), pp. 96-97.

83 Véase la carta de Grabmann del 7 de enero de 1917. En Hermann Köstler (1980): "Heidegger schreibt an Grabmann", Philosophisches Jahrbuch, 87: 107.

84 Cfr. GA 1: 215. Ahora bien, Duns Escoto, en opinión de Heidegger, no consideró el modo de ser de este ens como una realidad absolutamente objetiva; antes bien, supo diferenciar entre un modus essendi pasivus noemático, el modo como el ente está determinado como objeto, y el modus essendi activus noético, el modo como nuestros actos intencionales determinan el objeto (cfr. GA 1: 320). Además, véase Caputo (1974), pp. 104-105. 
cendentales, bien las categorías de ontologías regionales, ${ }^{85}$ aparecen en el horizonte luminoso del ens.

Ahora bien, de todos los transcendentales enumerados por Escoto, Heidegger, que todavía sigue interesado en hallar un fundamento de la matemática y de la lógica, centra su atención en dos categorías: las del unum y del verum. Por un lado, todo objeto es uno. El unum no añade nada al objeto, simplemente lo categoriza desde un punto de vista. En este caso, de un modo privativo: todo objeto es lo que es y no otra cosa ${ }^{86}$ Por el otro lado, el verum es una propiedad de todo objeto de conocimiento. Duns Escoto comprende la verdad de dos maneras: una, en términos de fundamento de la realidad, la verdad del ser; otra, en términos del intelecto que afirma o niega, la verdad del juicio. Para los escolásticos, la verdad reside formalmente en el juicio. ${ }^{87}$ El juicio unifica sujeto y predicado a través de la cópula "es". Y la determinación del status del "es" resulta esencial para una doctrina de las categorías. En un tono familiar al del neokantiano Lask, se afirma que "este 'est' no significa existir, un ser real al modo de los objetos sensibles o suprasensibles; antes bien, equivale a la expresión 'ser válido para'". ${ }^{88}$

Asimismo Heidegger muestra un ávido interés por la distinción entre el ente real y el ente lógico. Con ello se apunta hacia una primera diferencia ontológica entre ens logicum y ens reale, por la que el sentido lógico permite conocer las cosas reales. Nuevamente entraría aquí en juego una diferenciación entre un modus intelligendi passivus y un modus intelligendi activus. Nuestra actitud natural se movería en una prima intentio dirigida hacia los objetos y no hacia el sentido noemático. No obstante, ese sentido podría ser tratado en una secunda intentio en una especie de salto que iría del ens reale al ens logicum. Las palabras de Heidegger, aderezadas de husserlianismo, hablan por sí mismas.

En la vida natural, en el pensar y en el conocer nuestra conciencia está orientada hacia los objetos reales de la realidad inmediata; la escolástica describe

$85 \mathrm{El}$ estudio de éstas corresponde a la metaphysica specialis, que básicamente investiga los temas de Dios (teología), del mundo (cosmología) y del alma (psicología).

${ }^{86}$ Cfr. GA 1: 221. A continuación se presta especial atención a la diferencia entre el uno transcendental y el uno matemático. Aquél presenta una propiedad universal de todo objeto como tal, éste queda confinado a una esfera de objetos particulares, a saber, la esfera de los entes cuantificados. El alma, por ejemplo, es una unidad metafísica que no puede ser reducida numéricamente a nada cuantitativo. En todo momento, Heidegger remite explícitamente al artículo de Heinrich Rickert, "Lo uno, la unidad y el uno. Observaciones a la lógica del concepto de número" (Logos 1911/1912).

87 Cfr. GA 1: 268.

88

GA 1: 269. 
esta actitud con la expresión "prima intentio". A través de un peculiar cambio de perspectiva surge la posibilidad de dirigir el pensamiento sobre su contenido propio, secunda intentio. Todo lo existente en el mundo de los objetos metafísicos, físicos y psíquicos, así como los objetos matemáticos y lógicos son aprehendidos en el ámbito de la secunda intentio. Sólo en ese ámbito nos resultan cognoscibles los objetos. [...] Duns Escoto establece el dominio absoluto del sentido lógico sobre todos los objetos mundanos conocidos. (GA 1: 279)

Y, en sintonía con los resultados obtenidos en La doctrina del juicio en el psicologismo, la categoría que corresponde al contenido lógico es la validez. ${ }^{89}$

Sin embargo, la dicotomía ens reale y ens logicum lo coloca de nuevo ante el incómodo dualismo de un fluctuante reino histórico de la existencia de los objetos espacio-temporales y un atemporal reino transcendental de la validez lógica. Por un lado, ciencia y lógica pura; por el otro, historicismo y psicologismo. Pero insiste en que nos hallamos ante dos niveles ontológicos irreductibles que el filósofo debe separar con claridad. En este sentido, Heidegger señala:

Por muy estrecha que sea la conexión entre proposición y sentido, entre palabra y significado nos hallamos ante dos ámbitos de realidad diferentes. Los elementos lingüísticos se perciben por los sentidos de forma visual, acústica o motora; pertenecen al mundo de la existencia real, tienen duración en el tiempo. Significado y sentido, en cambio, se sustraen a cualquier percepción sensible y como tal no están sujetos a cambio alguno. (GA 1: 292-293) ${ }^{90}$

La refutación del psicologismo ya evidenció la oposición entre lo lógico y lo psíquico. El mundo del sentido conquistado en la secunda intentio es un reino de validez frente al de la realidad empírica cambiante. "El ens logicum, recalca Heidegger, se ha mostrado como un mundo propio frente al ens reale." 91 En este contexto de crítica al psicologismo, como ya se indicó en el apartado anterior, el joven Heidegger toma partido por la lógica, reprobando severamente toda epistemología de signo relativista.

Precisamente la primacía absoluta de la validez lógica frente a todas las teorías psicológicas, fisiológicas y económico-pragmáticas del conocimiento garantiza de modo absoluto e irrevocable la objetividad. (GA 1: 174)

El resultado final que arroja la doctrina de las categorías es que la verdad matemática y la verdad lógica son esferas independientes que no permiten

89 Cfr. Buren (1994), pp. 71-72.

90 Esta misma polaridad entre la materialidad del signo y la idealidad de lo lógico vuelve a hacer acto de presencia en Ser y tiempo bajo la forma de la distinción entre habla y significado. Para un comentario más extenso, consultar Rampley (1994), pp. 214-225.

91 GA 1: 290. 
ser reducidas a ninguna de las categorías naturales de Aristóteles. Por tanto, los significados se convierten en una ciencia distinta de la natural que se pasa a exponer en la segunda parte de la habilitación.

Esta segunda parte se concentra en el texto de la Grammatica speculativa, en la que Heidegger ve un anticipo de la doctrina del significado de Husserl. Los filósofos medievales del lenguaje sostenían que todo lenguaje empírico obedece a ciertos principios gramaticales últimos. Unos permiten ciertas proposiciones, otros las prohíben. Por ejemplo, no se puede completar la expresión sincategoremática "pero" por medio de "entonces si pero", mientras que sí resulta legítima y significativa la variante: "Es. inteligente pero orgulloso". "Entonces", "si", "pero" son expresiones que, en el primer caso, han sido combinadas inapropiadamente. En el caso de las conjunciones uno puede combinar un significado proposicional con otro, un adjetivo con otro, pero no dos conjunciones entre sí. Es tarea de la doctrina del significado salvaguardarnos de proposiciones sin sentido del tipo arriba indicado y estipular las reglas de acuerdo con las cuales las expresiones se pueden combinar formando plexos significativos. La elaboración completa de todas las combinaciones posibles y el estudio de las estructuras últimas del lenguaje constituyen, pues, el núcleo de una gramática universal. No se entienda en el sentido de hallar los rasgos empíricos comunes a todas las gramáticas existentes, sino en el de formular principios a priori a los que toda posible gramática se debe conformar. ${ }^{92}$ La grammatica speculativa, establece que el modo de significar (modus significandi) depende del modo de entender (modus intelligendi) y éste, a su vez, del modo de ser (modus essendi). ${ }^{93}$ La manera como el lenguaje significa algo tiene su fuente inmediata en la manera como el objeto es comprendido por el entendimiento y ambos tienen su raíz y su fundamento en la manera de ser del mismo objeto. En las proposiciones con sentido se produce entonces un tipo de estratificación que va de las expresiones (modus significandi) a través del significado comprendido (modus intelligendi) al ente que es inmediatamente intuido (modus essendi). En pocas palabras, previamente ha de existir el ens al que el intellectus asigna un significado que nos lo permite inteligir; pero para que el intelecto pueda conceder un significado a la cosa precisa haber comprendido ésta de alguna manera. Consecuentemente, el intelecto se alza en el elemento activo del conocimiento mientras que las cosas revisten la propiedad pasiva de ser conocidas. Una forma de interpretar a Duns Escoto

92 Cfr. Buren (1994), pp. 72-73 y Stewart (1979), pp. 361-362. Heidegger intenta dar validez a la idea, ya defendida por Husserl en el segundo volumen de Investigaciones lógicas, de una "gramática pura" al apropiarse de la "gramática especulativa" del tratado de Escoto.

93 Cfr. Caputo (1974), p. 102. 
en concordancia con la teoría de la expresión de Husserl, que confiere al sujeto una capacidad de donación de sentido análoga al intelecto.

Este intento de reactualización de la teología de corte tomista se enmarca de lleno en la llamada "disputa del modernismo". En el seno de este movimiento de renovación de la tradición católica medieval cobran una especial relevancia las investigaciones en torno a la "gramática especulativa"; esto es, el intento de exponer los principios lógicos y ontológicos últimos del pensamiento a partir de las estructuras gramaticales del lenguaje. El joven Heideggger tomó partido activo en este redescubrimiento de la filosofía del lenguaje medieval en su habilitación. ${ }^{94}$ Sin embargo, uno no puede evitar preguntarse: ¿qué es lo que movió a la teología de principios del siglo $\mathrm{xx}$ a interesarse por esta cuestión? En el ambiente histórico e intelectual de la época flotaba la pregunta acerca del papel que desempeña el sujeto pensante en su relación con el mundo, la sociedad, la cultura y, por supuesto, con Dios. Podría argumentarse que el antimodernismo católico se muestra contrario a las soluciones epistemológicas propuestas por las teorías científicias y el psicologismo. En contra del anonimato de la lógica, cuyos principios transcendentales se formulan sin tener en cuenta al sujeto concreto y sus situaciones vitales, y contra el psicologismo, que confunde la validez lógica de los argumentos con procesos psíquicos de evidencia, surge un renovado interés por las leyes estructurales del lenguaje de las que todo sujeto participa en tanto que hablante de una comunidad. Si se toma como punto de referencia una gramática especulativa en lugar de una lógica transcendental, entonces pasamos de un "yo pienso" anónimo a un "yo actúo" concreto y miembro de una comunidad de lenguaje igualmente concreta. Para los teólogos este giro supone enfocar a la razón desde la óptica de su historicidad. He ahí la verdadera enseñanza que extrae nuestro joven doctor en la habilitación.

94 Cfr. Schaeffler (1989), p. 295. No hay que olvidar que Heidegger todavía está obligado por las condiciones de la beca otorgada por la "Fundación Constantin y Olga von Schaezler en honor de santo Tomás de Aquino" a redactar una tesis en los parámetros filosóficos y teológicos tomistas. Nos detendremos brevemente en el asunto de la béca, pues permite comprender algunos aspectos de la personalidad de Heidegger. En su primera solicitud del 20 de agosto de 1913 Heidegger escribía: "El que firma esta carta y es su seguro servidor se permite solicitar humildemente al honorable capítulo catedralicio de Friburgo de Brisgovia la concesión de una beca de la fundación Schaezler. El humilde firmante tiene la intención de dedicarse al estudio de la filosofía cristiana en el marco de una carrera universitaria" (en Ott (1992), p. 89). Evidentemente, la concesión por tres años de la beca lo obligaba a permanecer fiel al espíritu tomista. Sin recurrir a un cuadro psicológico profundo, no resulta difícil imaginar el conflicto interno en el que el joven Heidegger tenía que hallarse, al verse completamente dependiente y limitado por la ayuda material de la Iglesia católica, como ya lo había estado durante los estudios medios y superiores. Para más información, consúltese Ott (1986), pp. 141-160. 
En Duns Escoto, pues, se encontraría un segundo aspecto fundamental: la capacidad del ser humano de desenvolverse práctica y libremente con las categorías universales. ${ }^{95} \mathrm{El}$ sujeto epistemológico del neokantismo, ahistórico y atemporal, no puede ignorar por más tiempo la textura histórica de la que está compuesto. Precisa ser vivificado y plenificado por el sustrato vivencial que determina en cada caso su existencia. Las categorías, incluso las categorías últimas de los trascendentia, no son simples formas inertes, pues el ser humano hace un uso práctico de ellas. Aquí resulta de vital importancia el principio de la determinación material de la forma de Lask, que permite tomar conciencia de ese nivel antepredicativo o fondo de significación que sustenta la vida y posibilita la aprehensión de las cosas como tal.

\subsection{El horizonte translógico del juicio: Lask y el principio de la determinación material de la forma}

Ciertamente la figura de Lask no ocupa un lugar central en la historia de la filosofía. A la sombra de neokantianos de la talla de Hermann Cohen o Ernst Cassirer, su obra parece haber ejercido una influencia más bien indirecta y sutil. Así lo reconoce explícitamente Heidegger en diversos momentos de su vida. ${ }^{96}$ El problema que une a ambos pensadores es el de cómo aprehender la multiplicidad de lo dado en la unidad del pensamiento. Dicho de otro modo, ¿cómo pasar de la indeterminación de la materia a la determinación de la forma? ${ }^{97}$ Un tema recurrente para todos aquellos filósofos que, en su regreso a Kant, pretendían zafarse de las redes del irracionalismo imperante en la filosofía de mediados del siglo xix. En este sentido, la postura de Lask resulta tremendamente sugestiva y va a proporcionar a Heidegger una solución a la cuestión de la validez y de la fundamentación de la lógica.

En contra de la tendencia académica al uso, Lask no se limita a una mera descalificación del irracionalismo en términos de lo simplemente noracional, a-lógico. En un sentido más amplio, 'irracionalidad' significa im-

95 Cfr. Rentsch (1989), pp. 38-41.

96 Véanse, por ejemplo, las palabras de agradecimiento en el "Prólogo" de la habilitación dirigidas a la memoria de Lask, muerto recientemente en el frente de guerra. En los cursos de 1919 se afirma sin remilgos que "Lask es una de las personalidades filosóficas más fuertes del momento" (GA 56/57: 180). Incluso el informe del escrito de habilitación redactado por su director, Heinrich Rickert, incide en la conexión de Heidegger con la "teoría metagramatical de sujeto-predicado de Lask, a cuyos escritos el autor (Heidegger) debe agradecer, mucho más de lo que él piensa, parte de su orientación filosófica y también de su terminología" (en Sheehan (1988), p. 117).

97 Tema de evidentes resonancias aristotélicas y que más adelante habrá de ocupar un lugar central en el pensamiento del joven Heidegger al abordar la cuestión de la unidad del ser y el significado múltiple del ente. 
penetrabilidad, imposibilidad de una aprehensión racional completa de la realidad. Desde el punto de vista de Lask, lo que caracteriza a la relación entre forma y materia es el hecho de que la forma abraza la materia y la reviste de lucidez teórica, la dota de significado para nuestro entendimiento. Cualquier cosa es susceptible de ser aprehendida en formas racionales, pero nada puede estar permeado completamente por ellas. La contingencia de la irracionalidad se extiende a la realidad individual, empírica y, en último término, histórica, resistiéndose a ser disuelta en conceptos universales y suprahistóricos. Este sustrato primario de la realidad es la precondición necesaria de toda actividad, ora téorica y abstracta ora histórica y práctica. De ahí el rechazo a la postura de Hegel que reduce todo lo real y particular a lo racional y universal. ${ }^{98}$ "Irracionalidad", en resumidas cuentas, denota la imposibilidad de una racionalización total. ${ }^{99}$

Precisamente Lask se alza contra un idealismo ahistórico y estático al invocar la hisoricidad del conocimiento humano y de sus categorías. Contra la universalidad abstracta, por ejemplo, de las normas jurídicas, el interés de la investigación filosófica se va desplazando hacia la irracionalidad irreducible de lo individual. El conocimiento filosófico sistemático deja paso a la vida y su capacidad de asir categorialmente el mundo. Con ello Lask se sitúa un peldaño por encima de la lógica al plantearse la necesidad de indagar cuál es el nivel de validez de las mismas categorías lógicas del pensamiento. ¿Cuál es la categoría de las categorías, la forma de las formas? Este planteamiento transcendental apunta en la dirección de la vida humana. Resula evidente que las filosofías de la vida de Georg Simmel y Wilhelm Dilthey, así como el vitalismo de Friedrich Nietzsche y el existencialismo de Sören Kierkegaard impregnan el ambiente intelectual del momento, pero en el neokantiano Emil Lask no encontramos signos neorrománticos ni poetizantes. Su inda-

98 Heidegger también confiesa en repetidas ocasiones que una "filosofía del espíritu vivo se halla ante la gran tarea de una confrontación con Hegel" (GA 1: $410 \mathrm{~s}$; véase también GA 56/57: 97 y GA 63: 59). El mismo Lask identifica bien pronto esta problemática. En su disertación sobre El idealismo de Fichte y la historia (1907) opina que este autor fue el primero en explorar las diferencias existentes entre lo empírico y lo analítico, lo individual y lo universal, la intuición y el concepto. Trasciende así el plano estrictamente epistemológico y coloca al individuo ante la realidad de la cultura, de la historia o del arte. Frente al sometimiento a las leyes de la naturaleza, el individuo conquista la posibilidad de desplegar libremente sus facultades.

99 LP: 221. Usamos la abreviatura LP para remitirnos al libro de Emil Lask, La lógica de la filosofía y la doctrina de las categorías, publicado en 1911. No es de extrañar, como apunta István Fehér, que tanto Lukács como Heidegger reaccionaran contra el impulso totalizador y homogeneizante de la tradición epistemológica dominante. Historia y conciencia de clase ofrece una perspectiva histórica de cómo el pensamiento burgués impide comprender la realidad social, mientras que Ser y tiempo presenta las consecuencias ontológicas del olvido del ser inherente a la historia de la metafísica (cfr. Fehér (1992), pp. 373 s). 
gación constata que en toda la ontología occidental las categorías, esto es, los conceptos fundamentales con los que se ha tratado de interpretar la relación del hombre con el mundo, con sus semejantes y consigo mismo, se elaboraron pensando únicamente en la esfera sensible. Lask opina, en cambio, que la tarea de una doctrina de las categorías también ha de comprender lo suprasensible; es decir, todo aquello que distingue al mundo humano de la simple experiencia. ${ }^{100} \mathrm{Y}$ este plan de reconstrucción de la metafísica le va a Heidegger como anillo al dedo. También Lask remite a la famosa expresión de Duns Escoto "fides non est habitus speculativus [...] sed practica". Esto significa que las preguntas vitales acerca de la vida humana no se deducen teóricamente a partir de la postulación de un ser objetivo, sino que obedecen a la propia actividad, al movimiento intrínseco de la vida misma.

En la formación de esta perspectiva ontológica, Heidegger apela desde su temprano artículo, Nuevas investigaciones sobre lógica, a la figura de Lask, mediador entre Rickert y Husserl. ${ }^{101}$ La primera tentativa de reformulación ontológica tiene que superar la visión de una historia de la filosofía reducida a historia de la doctrina de las categorías: ${ }^{102}$ Una visión centrada en las diez categorías de Aristóteles. El argumento central de la habilitación, que aplica las aportaciones de la lógica contemporánea a la doctrina de las categorías de Duns Escoto, sostiene la tesis de Lask de que las categorías aristotélicas no agotan la totalidad de las categorías existentes, pues tan sólo hacen referencia a cierto dominio de la realidad. ${ }^{103}$ Lejos de aplicarse a cualquier objeto de conocimiento, las categorías tradicionales se circunscriben exclusivamente al ámbito de la naturaleza. Una observación que ya habría realizado el mismo Escoto. ${ }^{104}$ Heidegger está sugiriendo que la doctrina clásica de las categorías es ciega ante otras esferas de realidad diferentes de la natural. Las categorías, pues, no pueden ser deducidas por abstracción del tipo de objetos estudiados, ni establecidas analógicamente por referencia a una instancia metafísica última. Sólo pueden ser descubiertas fenomenológicamente. ${ }^{105} \mathrm{El}$ proyecto que inicia el aspirante a profesor universitario se concreta en una expansión, esto es, una radical

100 Cfr. Rentsch (1989), pp. 46-47.

101 Cfr. GA 1: 24 ss y 32 ss. También "Prólogo" a Frühe Schriften (GA 1: 56).

102 Cfr. GA 1: 202.

103 Cfr. GA 1: 211. Además, Kisiel (1996), p. 203.

104 Cfr. GA 1: $287 \mathrm{~s}$.

105 Cfr. GA 1: 213. Una aproximación fenomenológica a la lógica da como resultado el reconocimiento de un tercer tipo de realidad. Junto a la realidad psico-física sensible y la realidad metafísica suprasensible, se sitúa la validez de los juicios. "Al lado del 'es' se da un 'es válido': el sentido, el factor idéntico y constante en el juicio que permanece irrevocable" (GA 1: 170). Además, Crowell (1994), pp. 60-62. 
re-elaboración de la doctrina de las categorías, capaz de hacer justicia a los otros dominios de realidad, como la historia o el arte, sin suprimir ninguno de ellos o reduciéndolos a otros, tal como sucede con el naturalismo o el psicologismo. ${ }^{106} \mathrm{El}$ conocimiento que aportan las ciencias empíricas es, por tanto, incompleto y precisa de una fundamentación ontológica ulterior.

En el contexto de esta necesidad de ampliación de la doctrina de las categorías, para que abarquen todo lo que pueda ser pensado, se produce un fructífero diálogo con Lask. Una vez que Kant ha establecido las categorías válidas para el conocimiento de la realidad natural, se trata de explorar las categorías del conocimiento filosófico mismo. Asunto que Lask considera vital para la filosofía. ${ }^{107} \mathrm{Si}$ estos diferentes dominios de conocimiento -arte, literatura, historia, etc.- obedecen a dinámicas propias, entonces habrá que encontrar una lógica primaria que las unifique y diferencie. "La lógica, afirma Heidegger en boca de Lask, precisa de categorías propias. Ha de existir una lógica de la lógica." 108 Una lógica transcendental como "autorreflexión y autoconciencia de la filosofía misma". ${ }^{109}$ La filosofía se transforma así en una ciencia originaria que indaga la naturaleza de las categorías, situándose en un nivel precognitivo en el que las formas puras se presentan a sí mismas como dadas.

¿Cuál es entonces la "categoría de las categorías", la última y más alta forma detrás de la cual ya no podemos interrogar más? El "ens commune ut maxime scibile" es el "algo en general, condición de posibilidad del conocimiento de cualquier objeto". ${ }^{110}$ Entre los neokantianos que se dedicaron al estudio de las categorías, como identidad, diferencia, unidad, multiplicidad, etc., Lask destaca por prestar una especial atención al "hay algo" (es gibt), la forma más elevada y pura creada por la subjetividad, pero al mismo tiempo la más vacía e indeterminada. Heidegger conecta esta cuestión con uno de los trascendentia medievales: el unum. Todo ens o algo es al mismo tiempo uno consigo mismo y diferente de cualquier otro. Por ello, todo objeto representa una relación de identidad y diferencia que hace que lo simple y lo múltiple se den co-originariamente como la mínima determinación necesa-

106 Cfr. Fehér (1992), p. 387. A la pregunta qué es lógica, la tesis de habilitación da un paso decisivo al afirmar que no es posible ver la lógica en la perspectiva correcta hasta que no se comprenda el contexto translógico, metafísico.

107 Cfr. LP: 22 s. La crítica laskiana a Kant insiste en que la investigación de aquellas categorías que posibilitan el conocimiento de la naturaleza ignora los conceptos a priori que hacen posible el conocimento de la historia. Lask añade que el esquema transcendental kantiano no sólo no procura las condiciones de posibilidad de otros muchos conocimientos empíricos, sino que tampoco puede dar razón de su propia validez cognitiva.

108 GA 1: 288.

109 LP: 210.

110 GA 1: 214-215. 
ria para poder aprehender cualquier objeto. ${ }^{111}$ En este nivel primitivo de donación preobjetiva no hay objeto si no está dado lo uno y lo otro. Hasta la "cosa" más simple, el puro objeto lógico, nunca aparece aislada; en sí misma siempre manifiesta una relación. Por ejemplo, la simple proposición "ens est" implica una relación lógica. El nombre ens es co-originario del estado de cosas del esse. "Todo objeto encierra un nexo relacional, incluso si sólo es cuestión de ser idéntico consigo mismo y diferente de otro". ${ }^{112}$ El unum que se predica de todo ens no añade nada nuevo al objeto. Únicamente le confiere claridad, revistiéndolo de un orden inicial sin el cual no podría ser pensado. En pocas palabras, asigna una forma a algún objeto de la realidad. En este primer nivel de determinación se aprecia la función del término "forma" en una teoría de las categorías: forma significa orden.

Cuando afirmamos que la realidad empírica manifiesta una estructura categorial particular, se dice que está formada, determinada, ordenada. (GA 1: 255)

Con ello, el "es" de un juicio ya no significa "existe", deja de ser un predicado real, y se tranforma en un ens rationis o ens logicum, para el que Lotze y Lask encuentran la feliz expresión "ser válido para". Una exigencia genuinamente kantiana la de considerar la validez del conocimiento independiente de las condiciones subjetivas o psicológicas en el que se verifica.

Entonces ¿dónde se produce la relación entre los dominios del ser real y el significado ideal? ¿En qué se diferencia la postura de Lask de la epistemología tradicional? En el hecho de que la idealidad de la validez se da únicamente en y a través de un contexto de significación. La existencia previa de una realidad mútliple, heterogénea, fluctuante y de un mundo compuesto de individuos, cada uno con su propia forma de singularidad, es la que posibilita la aplicación de las categorías. Resulta impensable que la forma pueda existir aparte (Aristóteles) o ser impuesta a lo material por el pensamiento (Kant). Antes bien, si existe una pluralidad de formas, entonces el pricinpio de individuación debe residir en la materia misma. ${ }^{113}$ Éste es el principio de la determinación material de la forma de Lask, por el que ningún objeto puede ser reducido a mero concepto lógico. Conocemos la materia del pensamiento a través de la forma en que se me presenta. La materia está arropada por la forma. Esa forma es inmediatamente experimentada, aunque no conocida. Vivimos en categorías como en un contexto que simplemente experimentamos como iluminación. La forma determina

111 Cfr. GA 1: 216 ss.

112 GA 1: 381. En palabras de Rickert, la aparente tautología ens est necesariamente implica una heterología. Un puro monismo sin oposiciones no puede ser pensado.

113 Cfr. Crowell (1994), pp. 63-64. 
los objetos y así también el orden en el que los objetos encuentran su lugar en el mundo. Lask sostiene que la forma no es nada más que una conformidad particular con lo material. Aporta cierto ordenamiento a las cosas. Arroja un momento de claridad sobre los objetos. ${ }^{114}$ Por tanto, la forma no es un principio metafísico, sino un principio de inteligibilidad. La novedad de su planteamiento, como reconoce Heidegger, consiste en aplicar el principio husserliano de la correlación interna de forma y materia. Ambos elementos responden a la pura relacionalidad.

Formas no son otra cosa que la expresión objetiva de los diferentes modos en los que la conciencia está referida intencionalmente a los objetos. Forma es un concepto correlativo; forma es forma de una materia. (GA 1: 319) ${ }^{115}$

Las formas, por tanto, han de ser completadas, plenificadas por la materia.

El principio de la determinación material de la forma nos permite apreciar que las categorías no tienen sentido sin el correlato de la intuición del objeto representado. Sin embargo, el isomorfismo que establece Lask entre el sentido del juicio y el objeto real sólo es una condición necesaria para el conocimiento, aunque no suficiente. Queda por resolver el problema de cómo se produce ese isomorfismo. Heidegger adopta una perspectiva fenomenológica y afirma que el conocimiento no es fruto de una comparación, sino de una plenificación. La claridad lógica del objeto resulta ininteligible sin la referencia al sujeto. La alusión a Husserl es crucial para la comprensión de la conformidad entre juicio y objeto. El noema, el contenido significativo de lo dado, no es nada más que el objeto mismo aprehendido en la secunda intentio de la reflexión, en la que la conciencia no está dirigida, como en la prima intentio, hacia "el objeto real en su realidad inmediata, sino hacia su propio contenido". ${ }^{116}$ La validez ya no es una categoría transcendental irreductible. Se funda en la intencionalidad: "la intencionalidad es la categoría que define el ámbito lógico", esto es, "el momento que determina el orden y caracteriza el ámbito de la lógica".117

Ahora bien, ¿cómo se produce esa conexión entre el sujeto y el objeto, el conocimiento y su objeto? La lógica medieval no logró ofrecer una explicación satisfactoria a este interrogante, pues carece de un concepto preciso de sujeto. ${ }^{118}$ La lógica contemporánea, representada por el realismo crítico

114 Cfr. LP: 69-75. La forma categorial guarda cierta semejanza con la materia, del mismo modo que en Ser y tiempo el útil se caracteriza por su conformidad con las estructuras referenciales del mundo circundante. Comentado extensamente en Kisiel (1983), pp. 165-185.

115 Véase, además, Rampley (1994) pp. 210-211.

116 GA 1: 279.

117 GA 1: 283 y 279 , respectivamente.

118 Cfr. GA 1: 401. 
de Külpe y el idealismo transcendental neokantiano, tampoco parece en disposición de clarificar esa conexión. El realismo crítico distingue entre conceptos empíricos y puros del conocimiento y mantiene que éstos últimos, las categorías, nos permiten predicar algo verdadero sobre el objeto mismo dado. La objeción de Heidegger señala que en la versión de Külpe "los objetos reales que han de ser determinados por el conocimiento no están como tal simplemente dados a la conciencia, presentes en la percepción, sino que ya han sido previamente tamizados por el filtro del conocimiento científico". ${ }^{119}$ Éste es precisamente el supuesto del idealismo de la escuela de Marburgo: el objeto de conocimiento sólo nos es dado en el juicio lógico válido. El problema que detecta Heidegger en estos defensores de la estética transcendental kantiana es que no "incorporan orgánicamente el principio de la determinación material de la forma a sus posiciones". ${ }^{120}$ Con ello se mueven en el terreno de una interpretación psicologista de Kant que desvincula la esfera noética de su correspondiente correlato noemático. Pero, como objeta Heidegger, si lo material está dado antes que nada a una conciencia precategorial, entonces una reconstrucción formal del pensamiento objetivamente válido pasa por alto el único ámbito dentro del cual puede hallarse el origen de las categorías: la inteligibilidad preteórica constitutiva de la propia vida. Es cierto que Lask consigue superar las insuficiencias de realistas e idealistas, pero deja sin resolver el asunto de cómo la materia determina la forma. ${ }^{121}$

La teoría del conocimiento de corte kantiano considera que la forma es el elemento activo que determina la materia. Ahora, en cambio, se ha de rertroceder del orden del conocimiento al orden del ser, al orden en el que la conciencia topa con los objetos. En contraposición al panlogismo de Hegel, las formas individuales no están unidas por relaciones lógicas recíprocas. Se encuentran delante de nosotros sumidas en un continuo heterogéneo, en una multiplicidad irreductible; en definitiva, participan de una realidad que se despliega como un fondo inagotable de posibilidades. En nuestro contacto con esa facticidad bruta de las cosas individuales sólo podemos aceptar su orden alógico de existencia y resignarnos a los límtes de la razón humana. ${ }^{122}$ El joven doctor Heidegger ilustra el momento de ese encuentro

119 GA 1: 403.

120 GA 1: 404. El realismo de Külpe mantiene la trascendencia del objeto de conocimiento. Pero su naturalismo no hace justicia a la problemática del sentido. El idealismo, por su parte, insiste en la primacía lógica del sentido válido, pero no toma en consideración el conocimiento precientífico.

121 Cfr. GA 1: 405.

122 Cfr. Kisiel (1996), p. 210. 
fáctico entre la existencia de una cosa y el conocimiento a partir de la contraposición de la "simplex apprehensio" y el "judicium".

La verdad de la "simplex apprehensio", el tener simplemente un objeto, no encuentra su contrario en la falsedad, sino en el no-conocer, en el no ser consciente de. Pero en cierto sentido representarse algo sólo puede ser llamado falso si ya se ha aprehendido el objeto bajo algún tipo de determinación. (GA 1: 320)

Heidegger está apelando al nivel antepredicativo, prejudicativo de lo directamente dado a la conciencia y que, por tanto, es anterior a la oposición de juicios falsos o verdaderos. Como recuerda Heidegger, haciéndose eco de la Sexta Investigación, "vivimos en la verdad", nos movemos en el seno de la intencionalidad "orientados hacia el objeto mismo en el reino noemático". ${ }^{123}$ Éste es el verdadero principio universal de realidad: el principio de la determinación material de la forma, que dicta que toda forma particular de significación se retrotrae a la realidad de lo dado.

Bajo la guía de lo dado (modus essendi), concluye Heidegger, que nos es da-

do como conocido (modus intelligendi) se alcanzan las formas de significado (modus significandi)" (GA 321)

¿Qué es entonces la realidad?

El modus essendi es todo aquello que puede ser experimentado y vivido en general; en un sentido absoluto, todo aquello opuesto a la conciencia, la robusta realidad que se resiste a ser sometida a la conciencia y que nunca puede dejarse a un lado. (GA 1: 318)

Por último, ¿cuál es la naturaleza de la experiencia inmediata que se corresponde con lo dado inmediatamente? Para los medievales esa facticidad última todavía remite a la providencia divina que así ha dispuesto la realidad. Esto conlleva que

el modus essendi es una realidad empírica dada inmediatamente sub ratione existentiae. Pero se produce aquí algo muy significativo que merece la pena ser tenido en cuenta: Duns Escoto caracteriza esa realidad empírica como algo situado bajo una "ratio", un punto de vista, una forma, un nexo intencional. (GA 1: 318)

En otras palabras, la experiencia inmediata de la realidad, depurada de connotaciones teológicas, es una experiencia categorial o, si se prefiere la 
expresión husserliana, una intuición categorial que reposa sobre algo preteórico en lo que simplemente vivimos antes de todo pensar sobre la realidad misma. Habitamos en la dimensión del significido sin tratarlo. Sólo podemos conocer los objetos, porque ya nos movamos en cierto nivel de relaciones con la realidad, en cierta familiaridad con la forma lógica: "las entidades de cualquier tipo sólo se pueden dar en y a través de un contexto de significado de carácter válido". ${ }^{124}$ Heidegger retoma de Lask la idea de una absorción preteórica y prerreflexiva en un mundo previamente comprendido, aunque sólo sea atemáticamente.

Lo que siempre se conoce, aquello sobre lo que también se emiten juicios, pertenece al ámbito del sentido; sólo en él se puede conocer y juzgar. Sólo en tanto que vivo en la validez, puedo tener conocimiento de lo existente. (GA 1: 280)

Vivir en un ámbito de validez equivale, en el lenguaje de Ser y tiempo, a poseer una comprensión preontológica del ser. ${ }^{125}$ En este sentido, "la temprana existencia de una doctrina de los significados en la escolástica medieval revela una fina disposición hacia la vida inmediata de la subjetividad y sus contextos inmanentes de significado, aunque sin haber alcanzado todavía un concepto preciso de sujeto". ${ }^{126}$ Este regreso a la esfera de la subjetividad y al nivel básico de los actos "remite al principio de determinación material de toda forma que, por su parte, incluye la correlación fundamental de objeto-sujeto". ${ }^{127}$ Con esta conclusión queda abierto el tránsito de lo lógico a lo translógico, el paso del sujeto epistemológico a la vida humana, que a partir de los cursos de 1919 habrá de cristalizar en una hermenéutica de la facticidad.

\subsection{Del sujeto epistemológico a la vida humana}

En algunos aspectos el itinerario del joven Heidegger también se ve confrontado, al igual que el de Lask, con el sentido de la irracionalidad de la vida y la búsqueda de un sistema filosófico. El camino que habrá de recorrer desde su tesis doctoral de 1913 hasta la publicación de Ser y tiempo en 1927 se nos presenta, desde la perspectiva actual, como el intento de conciliar las llamadas corrientes irracionalistas, historicistas o existencialistas con el ideal husserliano de una filosofía como ciencia estricta. Educado inicialmente en

125 Cfr. Crowell (1992), pp. 229-233.

126 GA 1: 401. 
parámetros escolásticos, si bien atento a la producción filosófica contemporánea representada por el neokantismo y la fenomenología, Heidegger empieza a esbozar un programa de renovación de la tradición metafísica al hilo de una elaboración explícita de la pregunta por el ser. En esta tarea la lógica pura y la epistemología, aunque herramientas indispensables en una fase preparatoria, resultan por sí mismas estériles, además de convertir la actitud teórica en la actitud filosófica por excelencia. ${ }^{128} \mathrm{Y}$, contrario a las tendencias relativistas de pensadores como Nietzsche, Dilthey o Kierkegaard que, en su defensa a ultranza de la existencia humana, rechazan todo pensamiento sistemático, la apropiación heideggeriana de la vida fáctica e histórica sirve, en esta fase de juventud, de punto de partida para una fundamentación de la lógica y una renovación de la metafísica. ${ }^{129}$

¿En qué consiste, pues, la fundamentación filosófica de la lógica? En la búsqueda de sus condiciones de posibilidad. Los juicios lógicos, como se viene insinuando a lo largo de este capitulo, presuponen una experiencia prelógica y precomprensiva de los objetos, ligada íntimamente al modo como vivimos y nos relacionamos con las cosas y situaciones de nuestro mundo.

No se puede ver la lógica y sus problemas en su justa dimensión hasta que el contexto del cual se interpreta se vuelva translógico. La filosofía no puede prescindir, a la larga, de la óptica que le es propia y por lo tanto de la metafísica. (GA 1: 405)

De manera que en la conclusión del estudio sobre Escoto se anuncia la problemática de fundar la validez objetiva de las categorías en la vida de la conciencia, la cual se caracteriza por la temporalidad y la historicidad. No se trata, evidentemente, de un retorno al psicologismo. La subjetividad que entra aquí en juego no omite la validez de las categorías. Se busca, más bien, enlazar explícitamente los dos aspectos de la historicidad de la vida humana y la validez intemporal de la lógica. El problema aquí esbozado excluye, empero, un discurso estrictamente transcendental, pues evita una consideración de las categorías como puras funciones del pensamiento. La reivindicación de la necesidad de ir más allá de la lógica ya manifiesta un elemento muy claro de polémica contra el neokantismo que habrá de acentuarse cada vez.

128 Cfr. GA 1: 186 s, 200, 403, 415. Un modo de pensar condicionado por el intelectualismo griego, según el cual la realidad inteligible sólo es accesible al entendimiento humano. Este prejuicio intelectualista, en cambio, discrimina por completo la realidad inmediatamente vivida.

129 Cfr. Fehér (1992), pp. 385-386. 
De este modo, el horizonte del problema de las categorías se plantea en términos de una "interpretación metafísico-teleológica de la conciencia", en términos de la noción del "espíritu vivo". ${ }^{130}$ La verdadera esencia del sujeto es histórica. Las categorías ya no se pueden deducir a partir de una conciencia atemporal. La lógica se funda en una apertura previa del mundo a la que se accede desde el sustrato vivencial y extralógico de la vida fáctica; esto es, no es dada a un sujeto cognoscente, sino a un ente que se ocupa del mundo. A partir de ese momento el sentido del juicio de la lógica va a pasar por una hermenéutica de ese ente, que no va a ser otro que el ser-ahí.

Las conclusiones a las que conduce un estudio a fondo de la filosofía de Escoto apuntan a que una posible solución al problema de las categorías, del significado y del juicio pasa por una cierta teoría de la subjetividad. ${ }^{131}$ Y esta subjetividad "sólo puede ser comprendida si se trae a colación la totalidad de sus realizaciones, esto es, su historia". ${ }^{132}$ Heidegger subraya que toda aproximación puramente formal al problema de las categorías está condenada al fracaso si no tiene en cuenta la cultura y la experiencia humanas del periodo histórico en que se emplean tales categorías. ${ }^{133}$ Esta subjetividad, ahora llamada "espíritu vivo" y que da cabida a las diferentes expresiones teóricas, prácticas y estéticas del espíritu humano, ya no se identifica con el sujeto de conocimiento.

En el reino de las formaciones del espíritu vivo, la actitud teórica sólo es una más entre muchas otras, por lo que resulta un error fatal confundir a la filosofía con una "concepción del mundo". [...] El sujeto epistemológico no alude al sentido fundamentalmente metafísico del espíritu. El espíritu vivo es como tal esencialmente un espíritu histórico. (GA 1: 406 y 407)

El punto de partida y, por tanto, el fundamento último de la lógica es la vida humana misma, la existencia histórica concreta ligada a todas las necesidades y aspiraciones, tanto prácticas como teóricas, de su tiempo. Se

130 GA 1: 406.

131 Cfr. Stewart (1979), pp. 366-372.

132 GA 1: 408.

133 Esta perspectiva sociológica de las categorías evoca, de alguna manera, a la figura de Durkheim. Para el sociólogo francés, la sociedad representa una entidad en sí misma que prescribe y orienta la acción del individuo. Las representaciones colectivas conforman así un mundo instituido de significado que pone a disposición un saber socialmente compartido. Esas estructuras de conciencia cumplen una función normativa y cognitiva: por un lado, proporcionan las tipificaciones de la conducta, fruto de la cooperación intersubjetiva y, por el otro lado, suministran las categorías básicas, como tiempo, espacio o causalidad, que permiten el decir y el representar sociales. Por ello, cabe hablar de una sociologización de Kant, pues las formas de entendimiento vienen dadas socialmente y no por la actividad de un sujeto transcendental. 
produce un desplazamiento de la clásica hegemonía del sujeto epistemológico en favor de lo que Heidegger no tardará en llamar en sus primeros años docentes "vida" y poco después "ser-ahô". Este intento de reconciliar la pureza del pensamiento con la inmediatez de la vida, la capacidad de situar los más abstractos problemas lógicos en la esfera del individuo es, sin duda, el aspecto de la filosofía de Escoto que más seduce a Heidegger. ${ }^{134}$ La grammatica speculativa, más allá de simbolizar una moda académica, muestra una sutil habilidad del hombre medieval a la hora de hacerse eco de la vida del sujeto. Esa vida del sujeto queda magníficamente recogida en la expresión de la "haecceitas", literlamente el aquí y el ahora de las cosas, que nos muestra con claridad que nuestra razón puede abstraerse de sí misma y distinguir entre aquello que las cosas son por sí mismas y aquello que añade nuestro pensamiento. ${ }^{135}$ Las cosas son por sí mismas un cúmulo de individualidades entre las cuales nuestro pensamiento se mueve comparando, combinando y ordenando. Somos nosotros los que proyectamos este continuo heterogéneo de las cosas individuales en el medio homogéneo de las categorías y de los conceptos. Sin embargo, las cosas son infinitamente mucho más que todo aquello representado por la conciencia humana y, además, son de tal manera que plenifican el contenido ideal de los conceptos.

En la tesis sobre Duns Escoto saca la conclusión, extraordinariamente importante para su filosofía, de que la heterogeneidad, riqueza y diversidad de la realidad no puede reducirse en grado suficiente a un tipo de ciencia que se oriente por el ideal de un significado idéntico; más bien, le corrẹsponde un lenguaje hablado en su historicidad, "la lengua viva en la peculiar movilidad de la significación y de su plenificación". ${ }^{136}$ La persuasión de que el órgano propio de la filosofía no es la lógica unívoca, sino el lenguaje hablado en su historicidad, es una constante que se mantiene firme en las diversas etapas del pensamiento de Heidegger. De modo que dentro de la terminología y de los planteamientos neokantianos hacen madurar en el joven Heidegger problemas y exigencias que ya no pueden resolverse en aquel ámbito. Problemas vinculados en reconocer la historicidad del espíritu vivo, esto es, como se dirá en Ser y tiempo, la efectividad de la existencia que hace imposible ver al sujeto de conocimiento como ese sujeto puro que está supuesto en toda posición de tipo transcendental. ${ }^{137}$

134 Cfr. GA 1: 203.

135 Para un análisis más detallado de la importancia del concepto de la "haecceitas" en el joven Heidegger como preludio de lo que a partir de los cursos de 1919 comenzará a denominar "vida" y luego "ser-ahi" consúltese Adrián (1999), pp. 220-228.

136 GA 1: 336. Véase, además, Safranski (1994), pp. 82-83.

137 Esta temática de la vida de la conciencia como historicidad implica un concepto de temporalidad irreductible al concepto de tiempo empleado en las ciencias físicas. Un asunto 
En cualquier caso, esta creciente acentuación de la vida lo lleva a interpretar y a fundamentar la lógica desde un contexto que va más allá de ella misma. Para el espíritu vivo no todo se agota en la actitud teórica. No es suficiente, dice Heidegger, "un resumen que recoja la totalidad de lo que puede saberse", pues se trata de "penetrar en la verdadera realidad y en la verdad real". ${ }^{138}$ La fuerza fundamentadora de la que hasta ese momento parecía disfrutar el sujeto de conocimiento de las ciencias se desplaza paulatinamente hacia el desdoblamiento histórico y temporal de la vida humana. Se consuma, de esta forma, el tránsito de un sujeto epistemológico a un ser-ahí fáctico y concreto. La realidad, en definitiva, no puede interpretarse como la traducción literal de un lenguaje lógico y, menos aún, como un reflejo del solipsismo psicológico. Antes bien, la realidad se despliega en toda su riqueza en la existencia socio-histórica de una vida humana expuesta a las contradicciones de las experiencias inmediatas y a la movilidad constante del tiempo.

De alguna manera esta determinación de la vida como instrumento de la filosofía ya está incubada en la mente filosófica del joven Heidegger, aunque en esos primeros años no haya conseguido explotarla al máximo debido a sus recientes vínculos teológicos y académicos.

El valor del pensamiento filosófico es algo más que una materia científica con la que uno ocupa su vida por cuestiones de preferencia personal y la voluntad de contribuir a la formación cultural. La filosofía habita simultáneamente en tensión con la personalidad viva y dibuja sus contenidos desde la profundidad de la plenitud de la vida. [...] Nietzsche, con su pietístico método de pensar y su capacidad plástica de presentación, ha puesto de manifiesto que la filosofía está determinada por el sujeto, que es el que "impulsa a la filosofía". (GA 1: 195-196)

Habrá de pasar la experiencia de la Primera Guerra Mundial para que ese caudal filosófico, retenido por la presa de las necesidades financieras y de las obligaciones académicas, pueda abrirse paso lenta pero fructíferamente en los próximos años. Este cambio de perspectiva va a preparar el camino hacia una fenomenología entendida como ciencia originaria de la vida, plenamente operativa a partir de los cursos del semestre de posguerra de 1919, y gradualmente irá adquiriendo desde las lecciones de 1923 los contornos de una hermenéutica de la facticidad.

que el joven Heidegger ya entrevió en su interesante lección de 1915, El concepto de tiempo en la ciencia histórica (cfr. GA 1: 415-433) y que empieza a adquirir un papel central en la filosófía de Heidegger a partir de la conferencia de 1924, El concepto de tiempo. Para más información, véase Adrián (1999), pp. 211-224.

138 GA 1: 406. 


\section{BIBLIOGRAFÍA}

Adrián, Jesús (1999), "Fenomenología de la vida en el joven Heidegger. De la tesis de habilitación a los cursos de 1919", Pensamiento 55/212, pp. 217-243.

- (1999), "Heidegger y el concepto de tiempo", Éndoxa no. 11, pp. 211-226.

Borges, Irene (1995), "De lo lógico a lo translógico. La cuestión del sentido en el joven Heidegger (1913-1916)", en Juan Arana (comp.), Saber y conciencia. Homenaje a Otto Same, Comares, Granada, pp. 71-94.

Borgmann, Albert (1978), "Heidegger and Symbolic Logic", en Michael Murray (comp.), Heidegger and Modern Philosophy, Yale University Press, New Haven, pp. 3-22.

Buren, John (1994), The Young Heidegger. Rumor of the Hidden King, Indiana University Press, Indianápolis.

Caputo, John (1973), "Language, Logic and Time", Research in Phenomenology, no. 3, pp. 147-155.

(1974), "Phenomenology, Mysticism And The 'Grammatica Speculativa': A Study of Heidegger's", Habilitations-schrif. Journal of the British Society for Phenomenology, 5/2, pp. 101-117.

Crowell, Steven Galt (1992), "Lask, Heidegger and the Homelessness of Logic", Journal of the British Society for Phenomenology, 23/3, pp. 222-239.

(1994), "Making Logic Philosophical Again", en Theodore Kisiel y John Buren (comps.), Reading Heidegger From the Start. Essays In His Earliest Thought, State University of Albany, New York Press, pp. 55-72.

Courtine, Jean-François (1996), "Les 'Recherches logiques' de Martin Heidegger. De la théorie du jugement à la vérité de l'être", en Jean-Françoise Courtine (comp.), Heidegger 1919-1929. De l'herméneutique de la facticité à la métaphysique du Dasein, J. Vrin, París, pp. 7-31.

Fay, Thomas (1974), "Heidegger on Logic: A Genetic Study of His Thought on Logic", Journal of the History of Philosophy, no. 12, pp. 77-94.

Fehér, Istvan (1992), "Lask, Lukács, Heidegger: the Problem of the Irrationality and the Theory of Categories", en Christopher Macann (comp.), Martin Heidegger. Critical Assessments II, Routledge, Nueva York, pp. 373-405.

Frege, Gottlob (1991), "Sobre sentido y referencia", en Luis Valdés Villanueva (comp.), La búsqueda del significado, Ariel, Barcelona, pp. 24-45.

Gadamer, Hans-Georg (1983), Heideggers Wege, J.C.B. Mohr, Tubinga.

García-Carpintero, Manuel (1996), Las palabras, las ideas y las cosas. Una presentación de la filosofía del lenguaje, Ariel, Barcelona.

García Gainza, Josefina (1997), Heidegger y la cuestión del valor. Estudio de los escritos de juventud, Newbook Ediciones, Pamplona.

Gumppenberg, Rudolph (1974), "Die transzendentalphilososphische Urteils-und Bedeutungsproblematik in Martin Heideggers Frühe Schriften". Akten des 4. Internationalen Kant Kongresses II, pp. 751-761. 
Heidegger, Martin (1978), "Das Realitätsproblem in der modernen Philosophie" (Artículo publicado en Philosophisches Jahrbuch der Görresgesellschaft en 1912), en Frühe Schriften, Vittorio Klostermann, pp. 1-16 (GA 1), Francfort del Meno.

(1978), "Neuere Forschungen über Logik" (Artículo publicado en Literarische Rundschau für das katholische Deutschland en 1912), en Frühe Schriften, Vittorio Klostermann, pp. 17-44 (GA 1), Francfort del Meno.

(1978), "Nikolai Bubnoff, Zeitlichkeit und Zeitlosigkeit" (Recensión publicada en Literarische Rundschau für das katholische Deutschland en 1913), en Frühe Schriften, Vittorio Klostermann, pp. 46-47 (GA 1), Francfort del Meno.

(1978), "Charles Sentroul, Kant und Aristoteles" (Recensión publicada en Literarische Rundschau für das katholische Deutschland en 1914), en Frühe Schriften, Vittorio Klostermann, pp. 49-53 (GA 1), Francfort del Meno.

(1978), Die Lehre vom Urteil im Psychologismus. Ein kritisch-positiver Beitrag zur Logik (tesis doctoral de 1913), en Frühe Schriften, Vittorio Klostermann, pp. 590188 (GA 1), Francfort del Meno.

(1978), Die Kategorien-und Bedeutungslehre des Duns Scotus (tesis de habilitación de 1915), en Frühe Schriften, Vittorio Klostermann, pp. 189-411 (GA 1), Francfort del Meno.

(1978), Der Zeitbegriff in der Geschichtswissen-schaft (lección de capacitación docente de 1915), en Frühe Schriften, Vittorio Klostermann, pp. 415-433 (GA 1), Francfort del Meno.

- $\left(1987^{16}\right)$, Sein und Zeit, Max Niemeyer Verlag, Tubinga [trad. castellana de José Gaos $\left(1987^{6}\right)$, El ser y el tiempo, Fondo de Cultura Económica, Madrid].

Hermann, Wilhelm-Friedrich (1997), La segunda mitad de Ser y tiempo, Trotta, Madrid.

Hobe, Konrad (1971), "Zwischen Rickert und Heidegger. Versuch über eine Perspektive des Denkens von Emil Lask", Philosophisches Jahrbuch der Görres Gesellschaft, 78, pp. 360-372.

Husserl, Edmund (1975), Logische Untersuchungen. Erster Band: Prolegomena zur reinen Logik, Martinus Nijhoff (Husserliana XVIII), La Haya [trad. cast. de José Gaos y Manuel García Morente $\left(1985^{2}\right)$, Investigaciones lógicas. 1. Prolegómenos a la lógica pura, Alianza, Madrid].

- (1984), Logische Untersuchungen. Zweiter Band: Untersuchungen zur Phänomenologie und Theorie der Erkenntnis, Martinus Nijhoff (Husserliana XIX/1 y $\mathrm{XIX} / 2$ ), La Haya [trad. castellana de José Gaos y Manuel García Morente $\left(1985^{2}\right)$, Investigaciones lógicas. 2. Investigaciones para la fenomenología y teoría del conocimiento, Alianza, Madrid].

Kisiel, Theodore (1983), "Heidegger (1907-1927), The Transformation of the Categorial", en Hugh Silverman, John Sallis y Thomas Seebohm (comps.), Continental Philosophy in America, Duquense University Press, Pittsburgh, pp. 165-185.

- (1996), "Why Students of Heidegger Will Have to Read Emil Lask", Man and World, no. 28, pp. 197-240.

Lask, Emil (1923), Die Logik der Philosophie und die Kategorienlehre, en Gesammelte Schriften II, J.C.B. Mohr, Tubinga. 
Lehmann, Karl (1964), "Metaphysik, Transzendentalphilosophie und Phänomenologie in den ersten Schriften Martin Heidegger (1912-1916)", Philosophisches Jahrbuch, 71, pp. 333-367.

Mohanty, J.N. (1988), "Heidegger on Logic", Journal of the History of Philosophy, 26, pp. 107-135.

Nolte, Emst (1998), Heidegger. Política e historia en su vida y pensamiento, Tecnos, Madrid.

Orth, E.W. (1992): "Martin Heidegger und der Neukantianismus", Man and World, 25, pp. 421-441.

Ott, Hugo (1986), "Der Habilitand Martin Heidegger und das von Schaezler'sche Stipendium", Freiburger Diözesan-Archiv, 106, pp. 141-160.

- (1992), Martin Heidegger. En camino hacia su biografía, Alianza, Madrid.

Pöggeler, Otto (1963), Der Denkweg Martin Heideggers, Günther Neske, Pfullingen. Rampley, Matthew (1994), "Meaning and Language in Early Heidegger: From Duns Scotus to Being and Time", Journal of the British Society for Phenomenology, 25/3, pp. 209-228.

Rentsch, Thomas (1989), Martin Heidegger. Das Sein und der Tod. Eine kritische Einführung, Piper, Munich.

Safranski, Rüdiger (1994), Ein Meister aus Deutschland. Heidegger und seine Zeit, Carl Hanser, Munich y Viena.

San Martin, Javier (1987), La fenomenología de Husserl como utopía de la razón, Anthropos, Barcelona.

Schaeffler, Richard $\left(1989^{2}\right)$, "Heidegger und die Theologie", en Gethmann-Siefert Annemarie y Otto Pöggeler (comps.), Heidegger und die praktische Philosophie, Suhrkamp, Francfort del Meno, pp. 286-312.

Sheehan, Thomas (1988), "Heideggers Lehrjahre", en John Sallis, et al. (comps.), The Collegium Phaenomenologicum, Kluwer, Dordrecht, pp. 16-117.

Stewart, Roderick (1979), "Signification and Radical Subjectivity in Heidegger's Habilitationsschrift", Man and World, 12, pp. 360-386.

Vattimo, Gianni (1986), Introducción a Heidegger, Gedisa, Barcelona.

Wolzogen, Christoph von $\left(1989^{2}\right)$, “'Es gibt'. Heidegger und 'Natorps Praktische Philosophie'", en Annemarie Gethmann-Siefert y Ott Pöggeler (comps.), Heidegger und die praktische Philosophie, Suhrkamp, Francfort del Meno, pp. 313-337. 